Article

\title{
Seismic Performance Assessment of an Existing RC Wall Building with Irregular Geometry: A Case-Study of a Hospital in Croatia
}

\author{
Mario Uros ${ }^{1, *} \mathbb{\infty}$, Snjezan Prevolnik ${ }^{2}$, Marta Savor Novak ${ }^{1}\left[\right.$ and Josip Atalic ${ }^{1}$ \\ 1 Department of Engineering Mechanics, Faculty of Civil Engineering, University of Zagreb, 10000 Zagreb, \\ Croatia; msavor@grad.hr (M.S.N.); atalic@grad.hr (J.A.) \\ 2 Department of Geophysics, Faculty of Science, University of Zagreb, 10000 Zagreb, Croatia; \\ sprevolnik@gfz.hr \\ * Correspondence: uros@grad.hr; Tel.: +385-98-1658-880
}

Received: 30 June 2020; Accepted: 7 August 2020; Published: 12 August 2020

check for updates

Featured Application: The methodology presented in the paper, which includes seismological measurements, structural testing of dynamical parameters, detailed numerical analyses based on three-dimensional finite element numerical models and methods of various complexities, may be used for the detailed seismic performance assessment of individual important buildings. Furthermore, the numerical modeling strategies described in the paper may be useful for evaluating irregular structures constructed as wall systems.

\begin{abstract}
Buildings of strategic importance should be able to resist seismic forces in accordance with potential earthquakes that may occur at the location and remain fully operational afterwards. However, many of them were constructed before the modern principles of seismic design were known (especially regarding detailing and ductility), and therefore may be considered substandard. The first step in mitigating the seismic risk of such structures is to assess their seismic performance and, in particular, to identify their structural deficiencies. This study presents a comprehensive methodology for the seismic performance assessment of individual buildings, applied to an existing reinforced concrete (RC) hospital. This building is of an irregular layout, constructed as a structural wall system, and it is located in the seismically active region of Croatia. It includes the assessment of seismic hazards on the location, ambient noise measurements, experimental determination of structural modal parameters, creation of a detailed numerical model calibrated with experimental data, and a seismic performance assessment using various analysis methods. As a result, the building collapse mechanisms were determined and critical structural elements identified, which is the basis for future actions directed to the reduction of its risk (e.g., applications of specific measures for a target retrofit, proposal of evacuation routes and safe places inside the building, etc.).
\end{abstract}

Keywords: seismic hazard; experimental measurements; data monitoring; ambient vibrations; wall system; irregular layout; nonlinear modeling; pushover method; nonlinear time-history analysis

\section{Introduction}

The seismic resistance of critical infrastructure buildings is a key feature of community resilience, as earthquakes have caused more than 745,000 casualties and reported losses amounting to 661 billion USD worldwide over the past 20 years (1998-2017) [1]. Hospitals and other important health facilities are counted as critical infrastructure and it is of the utmost importance that they remain fully operational after an earthquake. The seismic vulnerability of health facilities at a large scale has been studied by various authors (e.g., [2-8]). However, detailed seismic performance assessments 
of individual buildings, which should be made for all buildings of strategic importance, have been reported very scarcely. For example, in [9], the authors assessed the seismic vulnerability of an existing eight-story reinforced concrete (RC) hospital building, using numerical analysis and field monitoring data. The proposed methodology included the derivation of "time-building specific" fragility curves for a building. They concluded that field monitoring data is a very useful tool for determining the actual state of a building, which may differ significantly from the state assumed from the available design and construction documentation plans, and therefore, the structure may be more vulnerable than expected.

A further interesting approach to perform the seismic assessment of individual buildings, that may also be used for health care facilities, using several independent computer objects, has been presented in [10]. Ferraioli [11] evaluated the seismic vulnerability of the irregular RC hospital building of Avezzano in Italy using the pushover method, and studied the sensitivity of torsional inelastic responses to lateral force distributions, higher mode contributions, accidental eccentricity and controlled points for monitoring the target displacement. La Brusco et al. [12] studied the seismic performance of a real RC asymmetric hospital building, using different approaches to model (linear and nonlinear) and different analysis methods in accordance with the Italian technical code "Norme tecniche per le costruzioni" NTC 2008. They concluded that the applied analyses showed important differences in local and global seismic responses, and that the final results of the building safety level might be very different. However, they suggested the adoption of nonlinear procedures, but with caution and by expert engineers, because of the complex nonlinear behavior of structures that had to be tackled.

It is necessary to point out the lack of studies presenting a seismic assessment of irregular buildings consisting of lightly reinforced concrete walls. These structural systems are common in buildings in seismic areas and their performance has proved to be satisfactory in the case of very strong earthquakes [13], but if the ductile mechanisms are not provided, highly inelastic and dangerous complex mechanisms may occur [14]. Accordingly, considerable attention needs to be paid to creating element failure models.

A contribution to the seismic performance and loss assessment of old RC wall-frame buildings has been made by the authors of [15]. In this study, a loss estimation methodology for old RC frame-wall buildings characterized by non-ductile columns and RC walls made with smooth rebars and light transversal reinforcements has been proposed. These structures were analyzed in detail and their seismic vulnerability was assessed. The fragility functions of non-ductile RC walls with smooth bars were developed for the purpose.

An interesting case-study of an irregular high building with RC walls has been provided by [16] in which the authors identified the possible reasons of building collapse during the 2010 Chile earthquake. The damage of code-conforming reinforced concrete buildings during that earthquake also motivated the research presented in [17] in which a Chilean code-conforming reinforced concrete office building was designed, consisting of shear walls and moment frames. Its collapse potential was evaluated and fragility functions obtained through incremental dynamic analyses.

The assessment methodology and the modeling procedures for RC walls in a high-rise building has been presented in [18], where the assessment of the seismic capacity of tall buildings using nonlinear finite element modeling was conducted. In this study, the behavior of RC shear walls was validated through experimentally cyclic static tests. In addition, several pushover analyses and response history analyses were performed.

Due to many unknowns and the unreliability of the modeling, it is very important to determine the collapse mechanism of the structure on the basis of the global ductility being assessed, and the critical elements being detected. A valuable study on the topic of RC buildings is presented in [19].

Another interesting study that may be applied to instrumented buildings has been presented in [20] where authors have developed a decision-making framework for post-earthquake assessments. The proposed framework, illustrated on the testbed hotel, comprises seismic instrumentation which measures the dynamic response during a seismic event, uncertainty modeling, dynamic 
response reconstruction, damage estimation, and performance-based assessments and decision-making. This performance-based framework may be used by structural engineers, emergency managers and other relevant personnel to help them make informed and swift decisions regarding post-earthquake assessments of critical instrumented building structures.

The paper [21] presents and discusses five procedures for the assessment of the seismic performance of low-rise RC buildings at different levels of complexity, applied to three RC building examples (a bare frame, a frame with infills forming a soft first story and a dual frame-wall). The procedures differ regarding both the input data needed and the accuracy of their results. The results of the procedures at the simpler levels are more conservative, while the procedures at the higher levels yield, in the case of the tested examples, similar results, although they differ in the amount of input data and computational work needed. The authors concluded that the initial effective stiffness of the structure proved to be the most important quantity which determines the seismic demand, while the capacity/demand (C/D) ratio is not much influenced by the selection of the assessment parameter. Further research on the definitions of capacities, especially the shear capacity, has been suggested.

In line with the state-of-the-art experimental and numerical procedures for the assessment of the realistic seismic performance of structures, this paper presents comprehensive, but still simple and easily implementable, methodology. This methodology, explained in more detail in the next section, applies a thorough approach for the assessment of structural performances during seismic actions with the aim of reducing the uncertainties of all significant parameters in calculations. The analysis stages from the simpler linear analyses to more complex nonlinear ones complement and verify each other in order to avoid errors and a wrong interpretation of the results.

The assessment methodology is presented in detail on the case-study of an existing irregular RC hospital building, constructed as the wall system, located in a very seismically-active part of Croatia. The results of the comprehensive seismic performance assessment include the building collapse mechanisms and identification of critical structural elements. Following detailed seismic assessments, specific measures for a target retrofit are proposed. In addition to prevention measures, results of the performed assessment may be used to facilitate post-earthquake procedures (e.g., damage assessments and evaluations of building load-bearing capacities), particularly for situations in which a rescue of occupants has to be initiated by civil protection and rescue intervention teams and when partial collapses have to be resolved [22]. It is important to emphasize that the presented study contributes to a better understanding of the seismic performances of existing irregular structures comprising lightly reinforced concrete walls, as the previously published studies on the topic are very scarce.

\section{Methodology for Detailed Seismic Performance Assessments}

The proposed methodology is schematically presented in Figure 1.

As the first step, seismological ambient noise measurements are performed at the location in order to estimate the subsurface soil resonant frequency and amplification. The seismic hazard was estimated using the probabilistic approach and existing earthquake catalogue, as input data for all further analyses.

This stage is very important as it is necessary to reduce all uncertainties in the model as much as possible to assess the structural performance. A significant step is to acquire knowledge on the local site conditions and the seismicity of the building location. In this way, acceleration time-histories may be generated, representative of the earthquakes that may occur at the location. As the frequency spectrum of an earthquake, its duration and soil conditions, significantly affect the structural response (critical elements and failure mechanism), it is possible to focus more on the narrow range in which the response of the building is expected, and thus obtain more accurate results. 


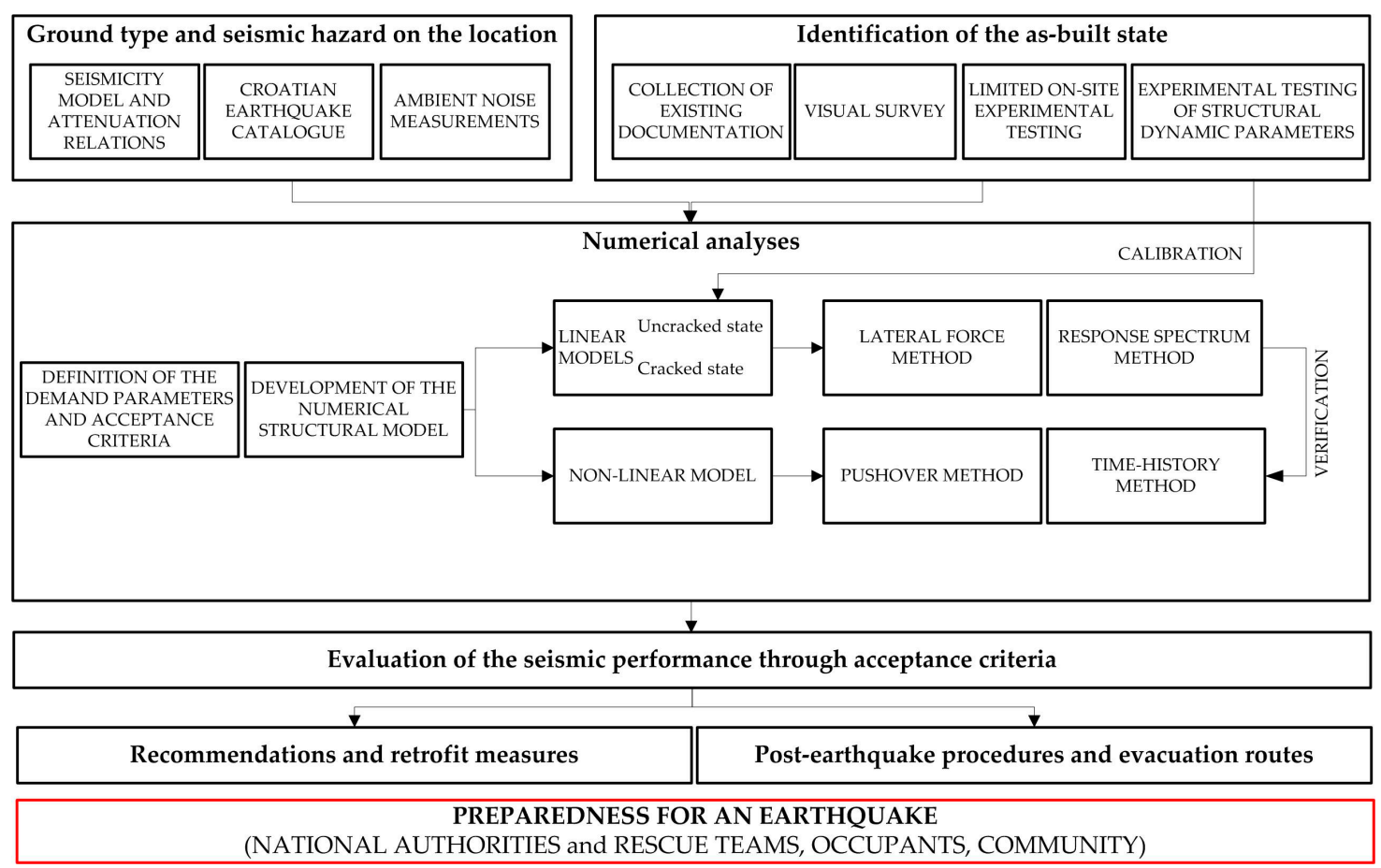

Figure 1. Proposed methodology for the evaluation of a building's seismic performance.

The as-built state of the building is determined based on the existing documentation, a detailed visual survey and collection of information from the occupants with regard to potential additional interventions on the structure, limited on-site experimental testing using ultrasonic devices, and the experimental testing of structural dynamic parameters using operational modal analysis (OMA). OMA may be performed by the frequency domain decomposition method (FDD), based on the decomposition of the auto power spectral density function of a multi-degree of freedom system to a series of independent single degree of freedom systems-one for each mode within the spectral range of the measurement. The procedure is based on the singular value decomposition of a matrix of auto power spectral density functions obtained in the measured structural response [23-25]. With the presumptions that the excitation is close to white noise in the observed spectral range, that the damping is low and that the modal shapes are geometrically orthogonal, the singular values represent the auto spectral densities of a single degree of freedom system, and the singular vectors represent the modal shapes. The singular value decomposition of a matrix of power spectral density functions $\left(\mathbf{G}_{y y}\right)$ obtained in the measured structural response results in

$$
\mathbf{G}_{y y}\left(\omega_{i}\right)=\mathbf{U}_{i} \cdot \mathbf{S}_{i} \cdot \mathbf{U}_{i}{ }^{H},
$$

which is defined at discrete frequencies $\omega=\omega_{i}$. Matrix $\mathbf{U}_{i}$ is a unitary matrix that contains singular vectors $\mathbf{u}_{i j}$ and $\mathbf{S}_{i}$ is a diagonal matrix that contains singular values. First, the singular vector $\mathbf{u}_{i}$ represents the modal shape at frequency $i$ and the responding singular value is the autospectrum power density of a single degree of freedom system at that frequency. This method is fast and efficient in the determination of eigen-frequencies and modal shapes. By determining the peaks of power spectral density function after the singular value decomposition, one can directly obtain the modal shape for the concerned eigen-frequency.

OMA is a very important step to assess the actual as-built state of all existing structures as it provides fundamental modal shapes together with corresponding natural frequencies and damping coefficients, which enable a more detailed evaluation of the dynamic behavior of the building and calibration of the initial three-dimensional finite elements numerical model. 
It is common knowledge that the determination of the as-built state plays a very important role in the assessment of existing buildings. The experimental testing of structural dynamic parameters may be very useful for this purpose, as it provides building eigen-frequencies, damping ratios, and modal shapes under ambient excitation. Although the data obtained using this experimental method are valid only for the stiffness levels corresponding to the vertical load combination, they are extremely valuable for the calibration of initial numerical models of irregular buildings (in plan and in height). A system of accelerometers needs to be installed relatively densely on each story, as the number and position of measurement points affects the accuracy level of the overall modal parameters. If the building geometry is irregular, it is necessary to check the potential independent vibration of structural parts in plan or in height. Particular attention should be given to the entrance spaces, which are usually extended from the floor plan, are often high and pass through several stories. Furthermore, in irregular buildings, critical elements are often located at the edge of the structure. It is recommended to install accelerometers in such places in order to determine the center of stiffness as accurately as possible as well as the locations of maximum displacements at the edges.

After the input data have been determined, numerical modeling strategies, demand parameters and acceptance criteria have to be adopted. Usually, development of the numerical model starts with the adoption of linear strategies, which may be calibrated with the results of OMA measurements. After this state of an uncracked structure and low amplitude excitations is verified and linear seismic methods applied, nonlinear models may be created. These detailed models, which include material nonlinearities of structural elements, are necessary to apply more complex nonlinear static and dynamic methods capable of capturing the performance of the structure during severe seismic shaking. For the nonlinear static (pushover) method, it is necessary to choose an appropriate model of material nonlinearity which can predict the real behavior of an element, appropriate displacement patterns and control points, while representative earthquake scenarios and corresponding accelerograms, artificial or real ones, have to be determined for the nonlinear dynamic time-history analysis using the most complex piecewise exact step by step method.

The seismic performance is assessed on the basis of the obtained results, including the building collapse mechanisms and identification of critical structural elements. Following detailed seismic assessments, specific measures for target retrofit may be proposed.

A nonlinear time-history analysis is very demanding, both computationally and in terms of time, and the input data should be as accurate as possible to obtain a reliable output. Moreover, the interpretation of the results is challenging, even for regular and simple buildings, and it is necessary to be an experienced professional/researcher in order to draw the right conclusions. Additional problem lie in the fact that older reinforced concrete buildings often have brittle failure mechanisms of critical structural elements which need to be accurately assumed and defined.

The described procedure is directed at limiting the area of key parameters scattering in structural performance assessments. The results of the previous, simpler analysis step are validated in each subsequent, and more complex, step, and the conclusions that have been drawn need to be confirmed or refuted. Much attention needs to be given to input data on seismic hazards, geometry, material properties and knowledge of construction methods in order to reduce the uncertainties to a minimum.

Ultimately, a complex numerical model formed and validated by the proposed methodology requires much less computational analysis, which is very important for complex and irregular structures. It is possible to devote more time to the interpretation of the results (also very important for complex and irregular structures), and it results in a more accurate assessment of the building failure mechanism and critical elements in the structure. It should be emphasized that a global failure mechanism is not critical in this type of building, but a local failure mechanism forms, which results in the structure exceeding the limit state of significant damage or near-collapse limit state. This approach to performance assessments is crucial in order to efficiently and reliably identify all critical local failure mechanisms, and thus propose target measures for their retrofit. 


\section{Description of the Case-Study Hospital Building}

\subsection{Introduction}

Although in Croatia seismic risk may be considered high [26], there are no systematic strategies directed to its mitigation [27]. Risk reduction activities mostly rely on the individual initiatives of research institutions, local authorities and civil protection teams, but they cannot be considered sufficient for creating the required systematic risk reduction strategy at local and national levels. A program for systematic seismic assessments and retrofitting buildings of strategic importance-such as schools, hospitals, major bridges and other essential facilities-does not exist. This is especially unfortunate taking into account the fact that most of the building stock in Croatia is very old (according to census data more than $40 \%$ of buildings were built more than 50 years ago), but still in use (and it will stay in use due to lack of financial resources to demolish old buildings and build new structures). The vulnerability of the Croatian building stock has further been demonstrated by an earthquake of M5.5 in the capital of Croatia, Zagreb, that occurred in March 2020, damaging more than 25,000 buildings [28]. More than $80 \%$ of hospital buildings were directly impacted by the earthquake and $17 \%$ were assessed as temporarily or permanently unusable.

Bearing all this in mind, the abovementioned individual initiatives may be considered very important, and one of these is the Interreg Readiness-Resilience Enhancement of ADrIatic basiN from the firE and SeiSmic hazards project (https://www.italy-croatia.eu/web/readiness) in which the study conducted in [22], partially presented in this paper, was performed.

\subsection{As-Built State of the Hospital Building}

General Hospital Dubrovnik (Figure 2) is a key building for the functioning of hospital services and rescue actions after potential earthquakes in the Dubrovnik-Neretva County, and is located in the most seismically-active region of Croatia with the reference peak ground accelerations exceeding $0.3 \mathrm{~g}$ for 475 years with return period earthquakes.

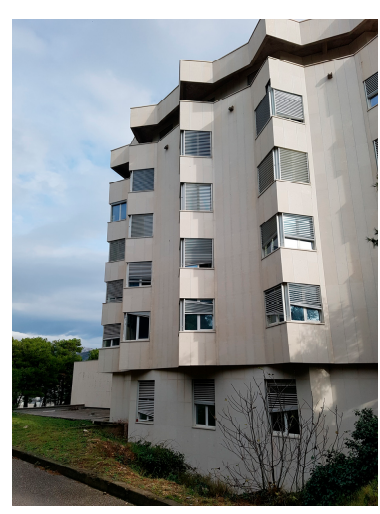

(a)

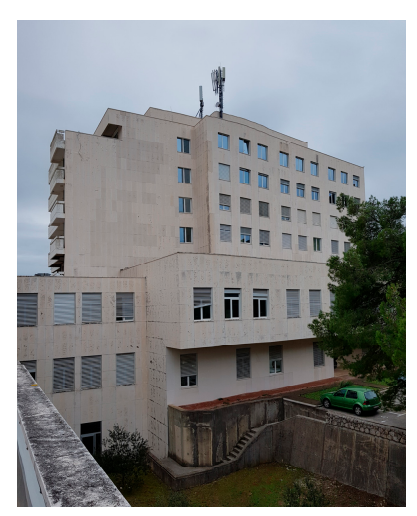

(b)

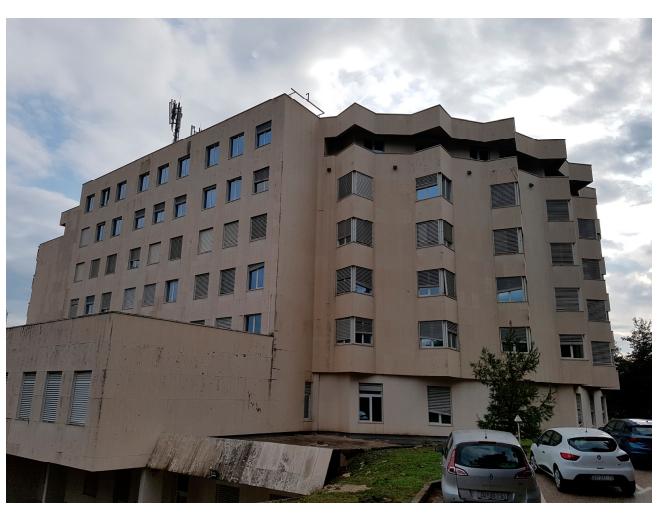

(c)

Figure 2. Building photographs: (a) south façade; (b) north façade; (c) north-east façades.

The building was designed and constructed in the 1980s. It has two stories below and eight stories above ground level, including the ground floor. The story heights are $4.5 \mathrm{~m}$ in the first two stories above ground level and $3.2 \mathrm{~m}$ in higher stories. The building is compact, but irregular in its plan (Figure 3) and height is. The outer building dimensions in the plan are approximately $51 \times 43 \mathrm{~m}$ and its height above ground is approximately $28 \mathrm{~m}$. The gross floor area of the ground floor and first story is $2123 \mathrm{~m}^{2}$, while the area of higher floors is $1537 \mathrm{~m}^{2}$. 


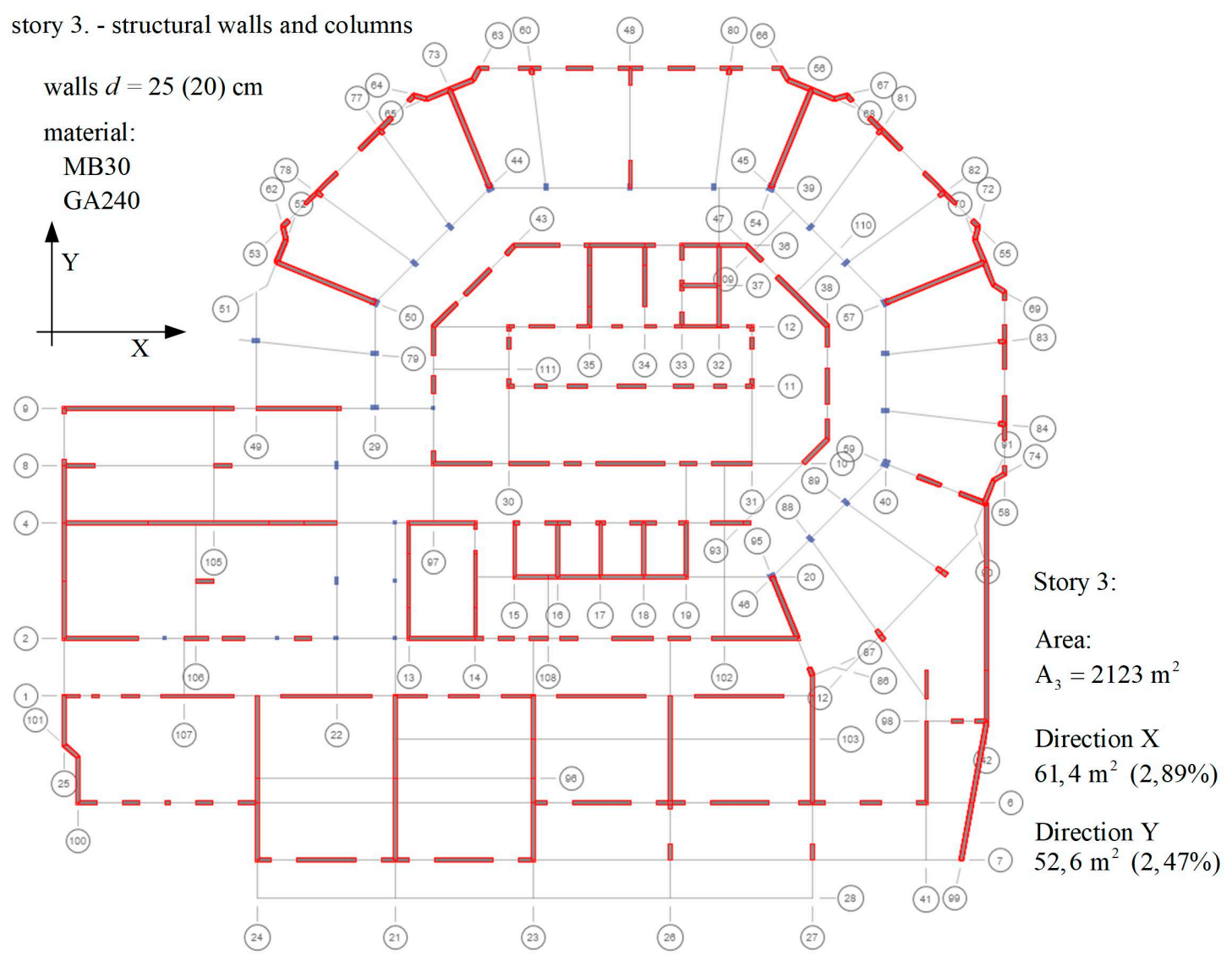

Figure 3. Layout of the story 3 (ground floor).

The original building documentation was collected from the city and the hospital archives. The dimensions of the structural elements were obtained from the drawings accompanying the original static design and checked on-site. It was confirmed that the as-built state mostly corresponds to the designed one. A reinforcement check was partially performed using a device for the ultrasonic testing of the reinforcement. Reinforcement spacing was identified for particular structural elements, but the rebar diameter and built-in reinforcement in some of the beams could be been reliably detected. Therefore, it was assumed to be in accordance with the static design and construction practices applied in the 1980s.

The building is compact, but irregular in plan, which is unfavorable for its structural seismic performance. Eccentricities in the building seismic response may cause significant forces in the structural elements located near the edge of the structure. It is also irregular in height according to Eurocode 8-1 [29]. It is constructed of reinforced concrete MB30 (C25/30) with smooth steel GA 240/360. The main load-bearing system consists of RC walls, mostly of $25 \mathrm{~cm}$ thickness, which continuously extend from the foundations to the roof, while the partition $\mathrm{RC}$ walls are not regular in height. The frame system negligibly contributes to the horizontal load-bearing capacity. RC walls are connected by coupled beams. In some elevations along the height, coupled beams are relatively deep (from $100 \mathrm{~cm}$ to $230 \mathrm{~cm}$ ) and it may be assumed that they are part of the wall system.

The partition walls are made mostly of reinforced concrete, 7 and $10 \mathrm{~cm}$ thick, and of gypsum. The sanitary facilities are mostly constructed with prefabricated RC panels with ribbed reinforcement and are linked to floors and ceilings by discrete connections. These panels have a certain stiffness and contribute to the building response due to ambient vibrations. However, it may be expected that these connections will break or that the hinge will be formed during intense ground shaking, so partition elements may lose their load-bearing capacity. However, it is not presented in the paper. 
Figure 4 presents the layout of stories three (ground floor) and five (the third story above ground level), where structural (grey) and non-structural RC elements (blue) may be observed. As it may be noticed from the figure, the cross-sectional area of all structural walls is much larger at the story three (ground floor) than at the story five (third story above ground level). As it will be shown later, the critical structural elements are located mostly at story five. Moreover, it may be observed from Figure 3 that the area of the walls in the $\mathrm{Y}$ direction is smaller $(2.47 \%)$ compared to $\mathrm{X}$ direction $(2.89 \%)$; therefore, earthquake loading in this direction would probably be more detrimental.

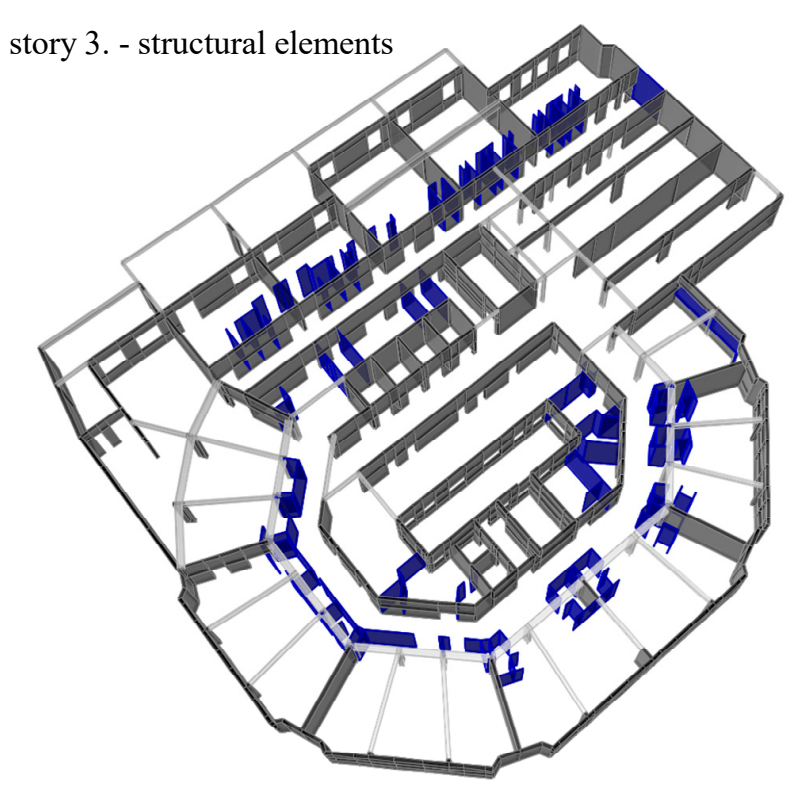

(a) story 5. - structural elements

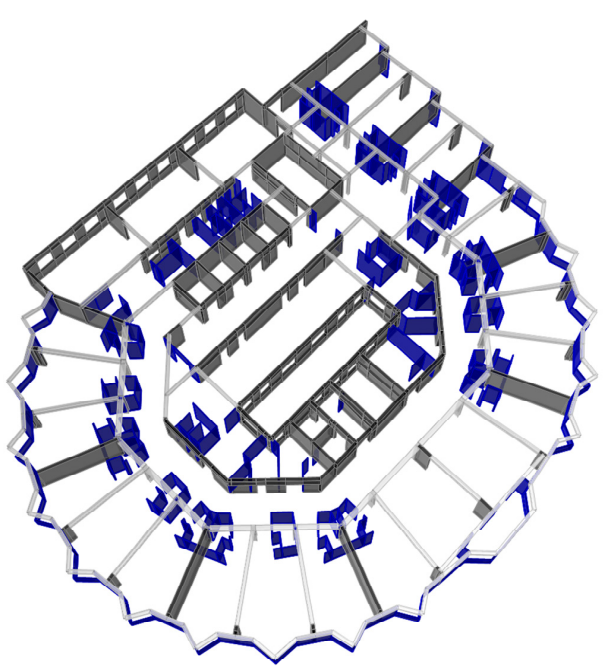

(b)

Figure 4. Structural and non-structural elements: (a) at story 3 (ground floor); (b) at story 5 (the third story above ground level).

The floor system comprises RC slabs of 15 and $12 \mathrm{~cm}$ thicknesses, with reinforcement assumed in accordance with the static design. Diaphragm action of the slabs may be expected.

The building has two inner RC staircases and an elevator core consisting of coupled walls.

Two stories below ground are partially embedded. An analysis of the embedding influence on the building displacements due to seismic loading was performed in the study. A nuclear shelter with structural walls with $50-60 \mathrm{~cm}$ thickness, and a $50 \mathrm{~cm}$ thick slab was built in the embedded part of the building. The foundation slab was $60 \mathrm{~cm}$ thick below the shelter.

Stripped foundations of different dimensions, transferring loads from structural walls to the ground, are constructed on two levels (basement and ground floor).

As it was previously mentioned, the building was designed and built in the mid-eighties of the 20th century, before the implementation of modern European seismic regulations [29]. However, seismic regulations from 1981 [30] covered structural ductility demands, accounting for hinge yielding and energy loss due to the concrete cracking, in order to avoid structural failures. Moreover, this seismic code took into account the building location in the seismically active zone and the importance factor for hospital buildings. Therefore, in the original design, the base shear coefficient calculated according to the code amounted to $0.15 \mathrm{G}$ ( $\mathrm{G}$ - the weight of the structure, approximately $15,000 \mathrm{t}$; comprises the walls, columns, beams and slabs with floor layers above, RC partition walls and additional dead load).

According to available information, standard rules of practice for construction in the seismically active areas were regularly applied in the region at that time, bearing in mind the devastating consequences of the 1963 Skopje earthquake. The basic difference between the seismic code from 1981 and modern seismic regulations lays in the reference peak ground acceleration which was significantly 
increased. Consequently, the internal forces in structural elements due to the seismic loading in accordance with modern codes are much larger than calculated in the original design.

A short description of the as-built minimum reinforcement is given in the following figure (Figure 5) and text.

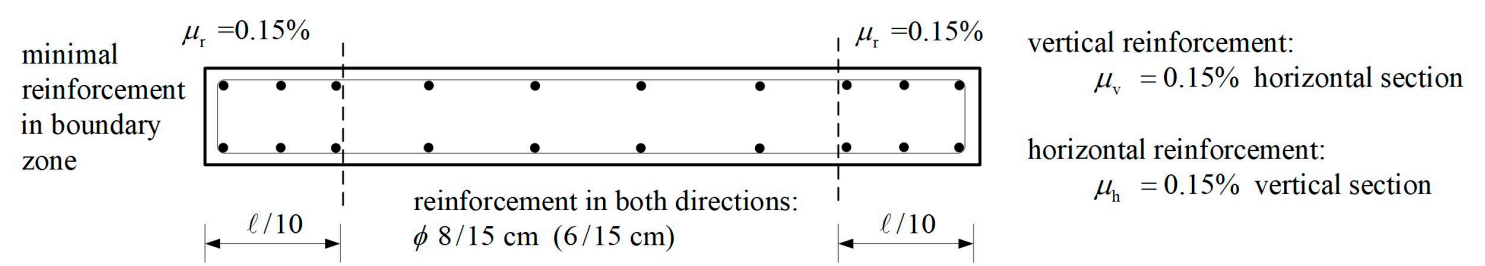

Figure 5. Minimal reinforcement in walls [30].

Walls and coupled beams have a longitudinal reinforcement of $\emptyset 8 / 15 \mathrm{~cm}$ and a shear reinforcement of $\emptyset 8 / 15 \mathrm{~cm}\left(\mathrm{~A}_{\mathrm{sw}}=6.6 \mathrm{~cm}^{2} / \mathrm{m}\right)$. Columns have minimal reinforcement according to the original design $(4 \emptyset / 20 \mathrm{~cm})$ and shear reinforcement $(\emptyset 8 / 15 \mathrm{~cm})$. Depending on the position, geometry and internal forces, some elements are reinforced more heavily, even at the limit of maximum reinforcement. The built-in reinforcement was taken into account during the calculation of each element capacity curve.

\subsection{Soil Type Characterization, Seismological Ambient Noise Measurements, Seismic Hazard and Ground Motion Generation}

According to the original documentation, the building's foundations were constructed in a layer of karstified limestone- a rock that can generally be classified as the ground type A according to Eurocode 8 [29]. This was confirmed by seismological ambient noise measurements which were performed on seven free-field locations on the site of the hospital using a Tromino seismometer. The horizontal to vertical spectral ratio (HVSR), [31], of $16 \mathrm{~min}$ long measurements with a sampling rate of $128 \mathrm{~Hz}$ was computed for all free-field measurements in order to quantify the effects of the subsurface geology on the seismic ground motion, primarily to estimate the subsurface soil's resonant frequency and amplification, thus enabling ground type classification according to Eurocode 8. The HVSR curve computed for the measurements performed in the immediate vicinity of the hospital building (FF_OBDD_1; FF_OBDD_4; FF_OBDD_5; FF_OBDD_6 and FF_OBDD_7) is flat, i.e., it has values lying between 0.5 and 2.0 (where a value of 1 is theoretically expected for a pure base rock outcrop) and without any clear peak within the wide range of frequencies (from below $1 \mathrm{~Hz}$ to up to a minimum of $25 \mathrm{~Hz}$ ), which is typical of rock sites or rock-like geological formations with possible thin layers of weaker material at the surface, and can be therefore classified as ground type A according to Eurocode 8 [29]. The results of two measurements performed on the locations that are the furthest away from the location of the building (FF_OBDD_2 and FF_OBDD_3) differ from the results of the measurements performed in the immediate vicinity of the building, indicating the possible lateral variations of the soil characteristics (Figure 6). 


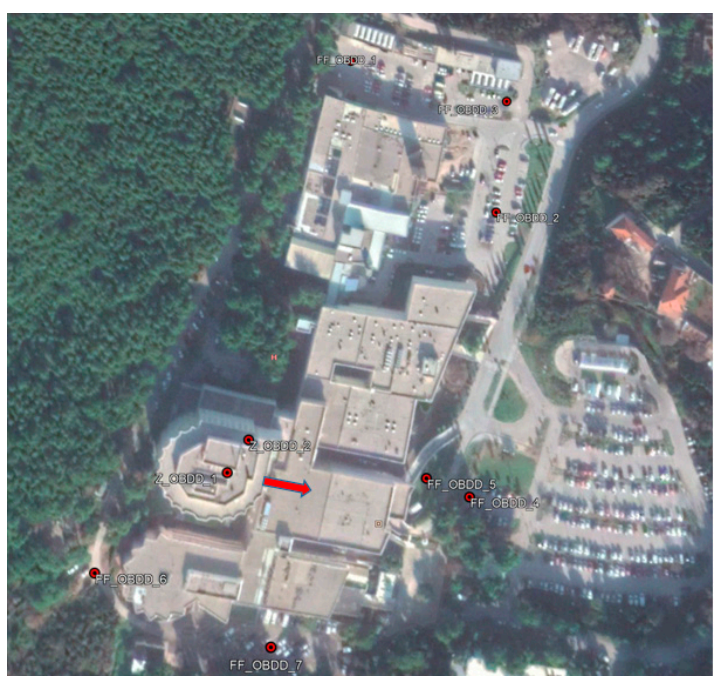

(a)

Max. $\mathrm{H} / \mathrm{V}$ at $0.22 \pm 7.43 \mathrm{~Hz}$ (in the range $0.0-64.0 \mathrm{~Hz}$ )
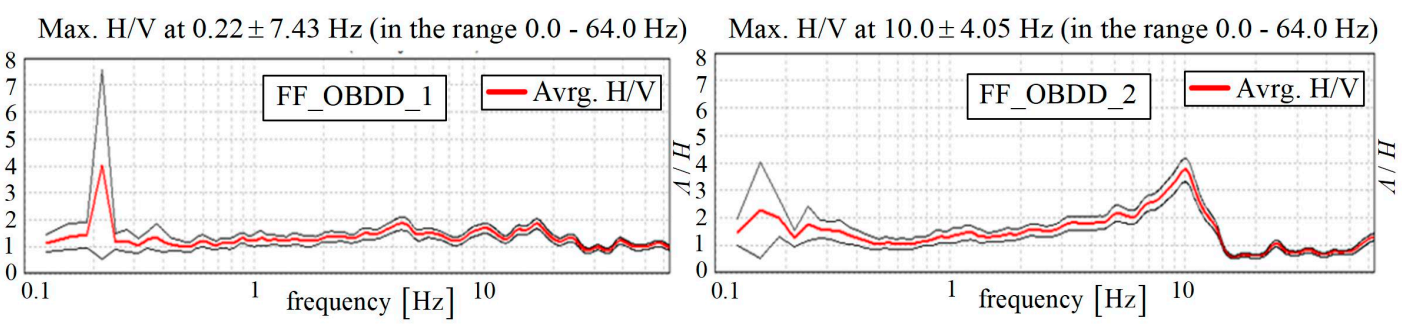

Max. H/V at $10.09 \pm 5.52 \mathrm{~Hz}$ (in the range $0.0-64.0 \mathrm{~Hz}$ )
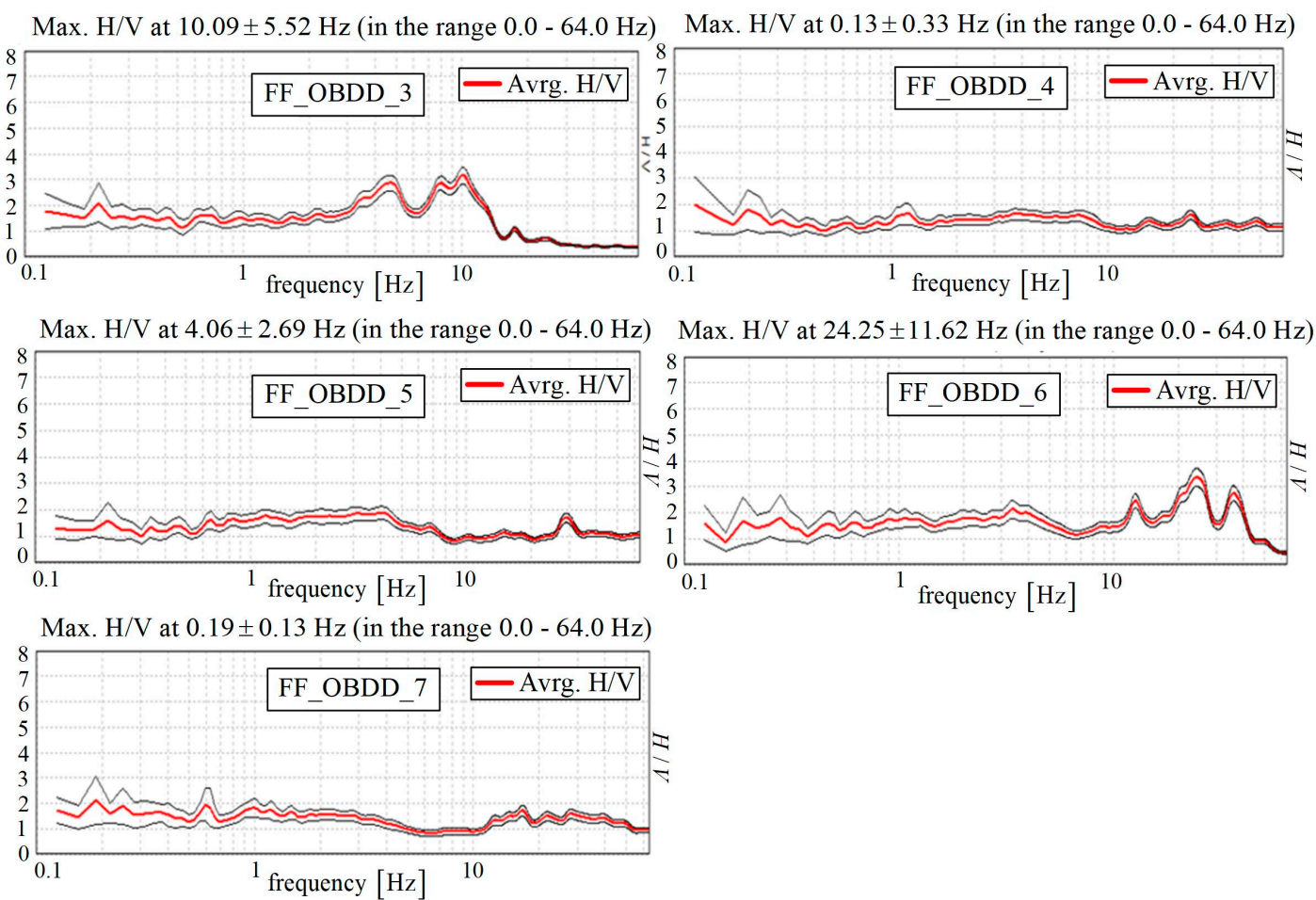

(b)

Figure 6. (a) Locations of ambient noise measurements performed on the site of the hospital building. Red arrow indicates the orientation of the instrument, which was the same for all measurements [32]; (b) horizontal to vertical spectral ratio (HVSR) curves computed for the individual free-field measurements performed in the vicinity of the building. Red line displays the averaged HVSR spectra and black lines display a confidence interval of $95 \%$. 
In addition, a continuous instrumental monitoring of the building was also performed using a seismometer and the data acquisition system installed on the sixth floor with the sensor oriented along building's longitudinal direction, for a time period of 98 days (more than three months). These measurements were used to monitor its structural integrity and response to ground shaking induced by an earthquake. Unfortunately, no continuous measurements in the nearby free-field were performed. However, ambient noise measurements were performed in the free-field in the vicinity of the building on several locations, and the HVSR curve computed for these measurements is flat without any clear peak within the wide range of frequencies from below $1 \mathrm{~Hz}$ to up to a minimum of $25 \mathrm{~Hz}$ (see Figure 6). This means that the uncorrected spectrum measured on the sixth floor should be representative of the building's response. During this time period, a valuable high-quality data set was collected, which enabled the monitoring of fluctuations of the building's fundamental frequency. The spectrograms computed for two horizontal components (longitudinal and transversal) clearly indicate the first three modes of the building's dynamic behavior which are in excellent agreement with the results obtained by the OMA analysis (see Table 1). Moreover, continuous measurements enabled insight into the long and short term variability of the building's fundamental frequency. The long term variability of the frequency for the first three modes is observed for both components. This variation might be correlated to the seasonal change of distinct meteorological parameters. Unfortunately, since there is no meteorological station in the immediate vicinity of the building, a more detailed analysis in the sense of correlating observed fluctuations to weather conditions could not be done. Short term variations are linked to the change of the amplitudes of the excitation. This is clearly displayed on the spectrogram for two horizontal components of the recording made during one week (Figure 7). Noticeable differences were observed between the working hours (characterized with higher amplitudes in red color) and more quiet periods during the night (characterized with lower amplitudes). During the time period when continuous measurements were performed, there was no earthquake strong and close enough to cause damage to the building, nor any other events that had caused a change in the building's structural state of health.

Table 1. Eigenvalues and damping ratios obtained by testing.

\begin{tabular}{cc}
\hline Eigenvalue \pm Standard Deviation $\mathbf{( H z )}$ & Damping Ratio \pm Standard Deviation (\%) \\
\hline $3.25 \pm 0.01$ & $1.77 \pm 0.59$ \\
$3.81 \pm 0.02$ & $1.72 \pm 0.63$ \\
$4.50 \pm 0.05$ & $2.04 \pm 0.64$ \\
\hline
\end{tabular}

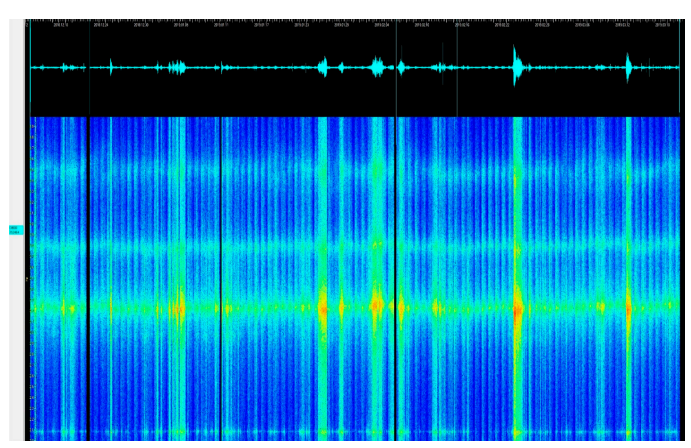

(a)

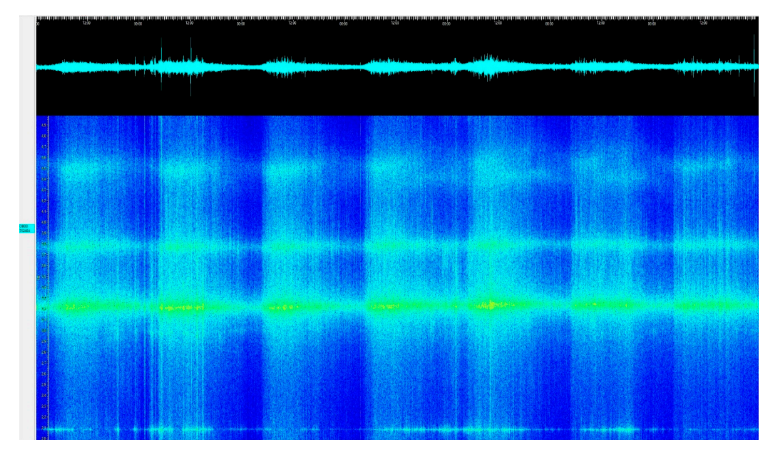

(b)

Figure 7. Spectrogram of the transversal component of the velocity spectra measured on the sixth floor in the hospital building in the frequency range of $2-5 \mathrm{~Hz}$. (a) Time period of the entire working time of the installed instrumentation (98 days); (b) time period of one week. Similar observations are also clearly present in the longitudinal component of the spectra.

A probabilistic seismic hazard assessment (PSHA) was performed for the location of interest based on the Croatian Earthquake Catalogue (CEC) and available data on the seismotectonic characteristics 
of the broader area. The hazard is generally described by the statistical probability of exceedance (frequency of exceedance) of the selected parameter in the given time interval. At the investigated location, it was expressed as the peak ground acceleration (PGA) on soil type A according to Eurocode 8 for the return periods of 95, 225, 475 and 2475 years. The seismic hazard for the return periods of 95 and 475 years is defined by the seismic hazard map of the Republic of Croatia compiled in 2011 [33]. For the return periods of 225 and 2475 years, the seismic hazard was estimated using the same procedure (with the same seismicity models—smoothed seismicity—and attenuation relations) and the same Croatian Earthquake Catalogue as used for the compilation of the seismic hazard map of the Republic of Croatia. This kind of procedure for seismic hazard estimation was applied, for example, in the works of [34-37]. The peak ground accelerations for soil type A at the location of the building are determined as: $0.16 \mathrm{~g}, 0.21 \mathrm{~g}, 0.30 \mathrm{~g}$ and $0.51 \mathrm{~g}$ for the return periods of 95, 225, 475 and 2475 years.

In accordance with the assessed hazard, artificial and simulated accelerograms were generated for the location. Unfortunately, accelerograms of a strong earthquake have never been recorded on the bedrock in the greater area of the hospital. Artificial accelerograms were generated using the artificial accelerogram generation method [38] with the SeismoArtif tool [39]. This method defines each artificial ground motion modifying the starting random process through the use of a selected envelope shape and a power spectral density function (PSDF) calculated from the velocity target spectrum which is selected before the execution. With both the target spectrum and the envelope type defined, an artificial accelerogram is generated and a comparison between its response spectrum and the target spectrum is given, including the mean error in percentage, coefficient of variation, and PGA of the accelerogram. The target spectrum for the generated artificial accelerograms was the Eurocode 8 elastic response spectrum of type 1 (which is in use in Croatia) for the ground type A and for $5 \%$ viscous damping. Four levels of seismic action corresponding to four different return periods of interest were taken into consideration. The minimum duration of the stationary part of the accelerograms was equal to $10 \mathrm{~s}$. Finally, 12 three-component (comprising of two horizontal orthogonal components and one vertical) artificial accelerograms were generated, three for each level of seismic action.

Simulated accelerograms for the investigated location were calculated for the bedrock level using the following assumptions:

1. The representative shape of the Fourier's amplitude spectrum $\left(S_{0}\right)$ of the accelerogram on the bedrock level can be described as a function of an earthquake magnitude and the distance between its hypocenter and the studied location, as proposed by [40,41];

2. Phase spectrum is a random function of frequency;

3. Duration of the significant part of shaking is in conformity with the expression proposed by [42];

4. The shape of an accelerogram envelope can be modeled using Berlage's function, with its parameters brought into conformity as in Assumption 3;

5. The surface ground layers' amplification effect on the seismogram spectrum can be described by the convolution of a synthetic accelerogram on the bedrock level with the response of a representative geotechnical model on location. In this report, this part of modeling has not been done since the ground type on the location of interest is estimated to be type A.

The synthesis procedure is carried out by iteration, until the spectrum of the calculated accelerogram showed no significant deviation from the target spectrum $S_{0}$.

Because of the assumption of randomness with regard to the phase spectrum, the above conditions are not sufficient to define uniquely the synthetic accelerogram. This fact, however, is not crucial, because all the generated accelerograms will have very similar response spectra because of the equal duration and very similar amplitudes of the Fourier spectra. An accelerogram with characteristics most similar to average characteristics of a large set of theoretical accelerograms will be chosen as the representative accelerogram.

The characteristics of the accelerograms of nearby and more distant earthquakes, as well as those of moderate and strong earthquakes, exhibit substantial differences. This is why obtaining a full 
picture requires calculating synthetic seismograms so that they could cover-to a rational extent-all the cases important for the earthquake hazard at the studied location. In accordance with seismic hazard assessment, it was considered, for the four deterministic earthquake scenarios for the hospital location selected in the manner, that the reasonably expected PGA from an earthquake anticipated in each scenario simulates ground motion for the selected return periods (RPs) of interest:

1. An earthquake at the very location $(D=5 \mathrm{~km})$ with a focal depth of $h=5 \mathrm{~km}$ and with a magnitude of $M=5.7, \mathrm{RP}=95$ years, $\mathrm{PGA}=0.16 \mathrm{~g}$;

2. An earthquake at an epicentral distance $D=30 \mathrm{~km}$ with a focal depth of $h=10 \mathrm{~km}$ and with a magnitude of $M=7.4, \mathrm{RP}=225$ years, $\mathrm{PGA}=0.21 \mathrm{~g}$;

3. An earthquake at an epicentral distance $D=15 \mathrm{~km}$, with a focal depth of $h=15 \mathrm{~km}$ and with a magnitude of $M=7.2, \mathrm{RP}=475$ years, $\mathrm{PGA}=0.30 \mathrm{~g}$;

4. An earthquake at an epicentral distance $D=10 \mathrm{~km}$, with a focal depth of $h=15 \mathrm{~km}$ and with a magnitude of $\mathrm{M}=7.5, \mathrm{RP}=2475$ years, $\mathrm{PGA}=0.51 \mathrm{~g}$.

As a large number of accelerograms were generated, only one set of the simulated ones in horizontal directions per scenario with corresponding elastic response spectra will be presented in Figure 8. The labels of the accelerograms in the figure have been created using the following rule: the return period of the scenario is at the beginning of the label, s_th denotes the simulated time-history and the horizontal components in two directions are marked with ae i.e., an.

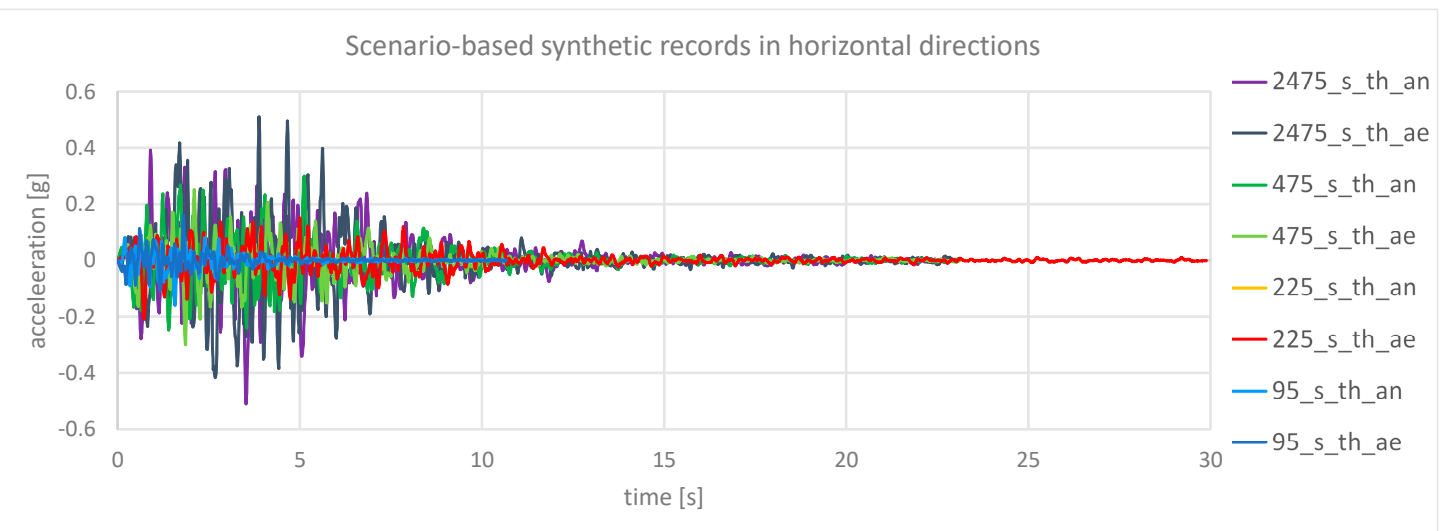

(a)

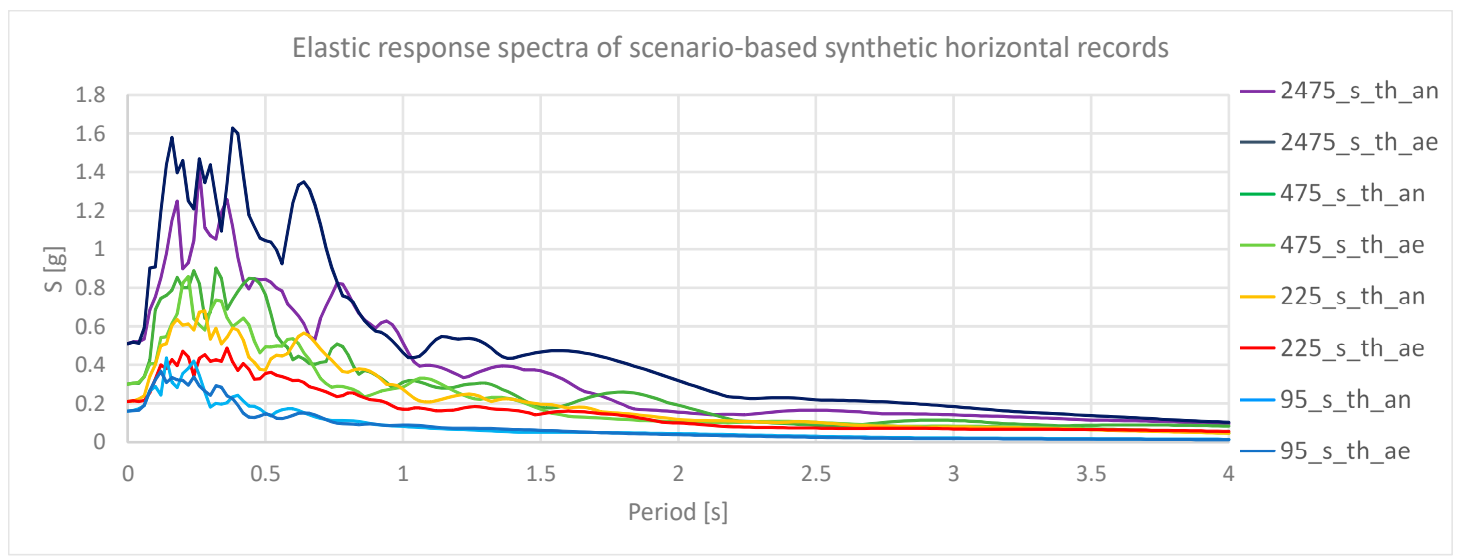

(b)

Figure 8. Deterministic earthquake scenarios: (a) scenario-based acceleration records in horizontal directions; (b) corresponding elastic response spectra. 


\subsection{Experimental Determination of Structural Modal Parameters}

The experimental determination of structural modal parameters (eigen-frequencies, damping ratios, modal shapes) was conducted using OMA. OMA implies the analysis of structural responses under operational conditions when the structure is excited by forces caused by ambient or natural actions. The measurement was performed at 145 measurement points. This implies 15 measurement points on every floor, except floor -2 below ground (a part of the floor is backfilled). The majority of the measurement points were located in corridors and stairways close to vertical structural bearing elements. Accelerations were measured in two orthogonal horizontal directions at each measurement point, so a total of 290 degrees of freedom (DOFs) was taken into account. The following table shows the eigenvalues and the corresponding damping ratios obtained by the performed measurement. Figure 9 shows a characteristic record of the singular values of the autospectral densities matrix, in which the peaks represent the building eigen-frequencies, while the experimentally obtained modal shapes for the first three eigen-frequencies are shown in Figure 10.

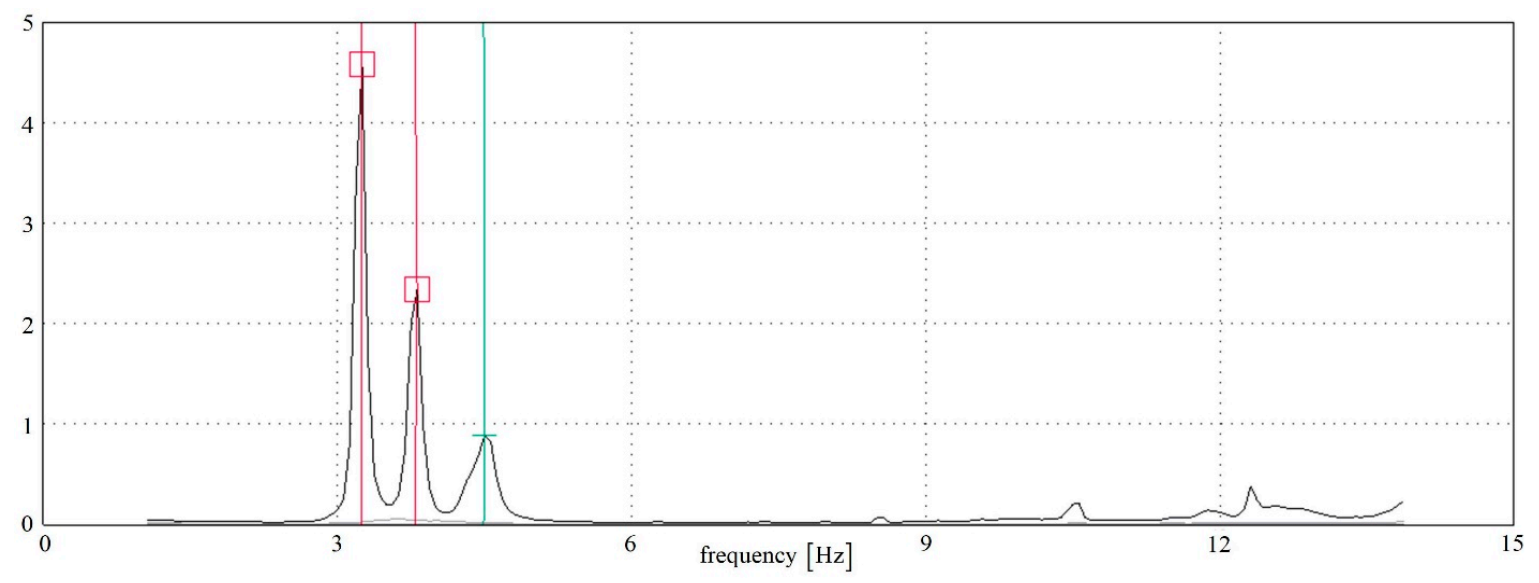

Figure 9. Record of the singular values of the autospectral densities matrix.

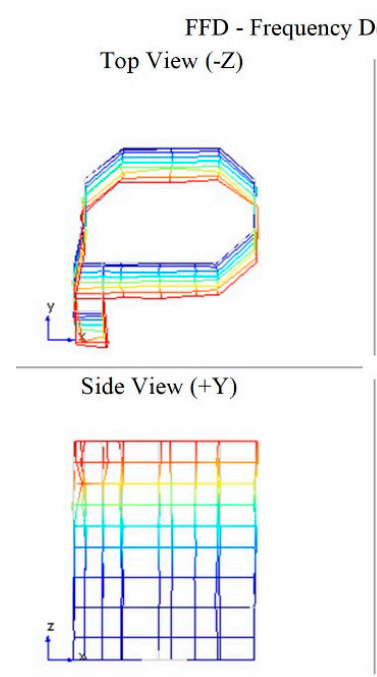

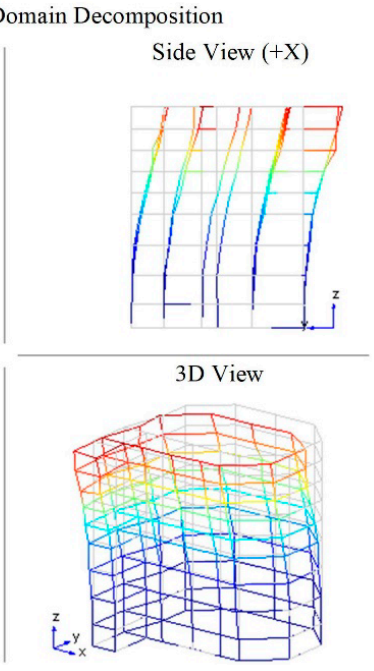

(a)

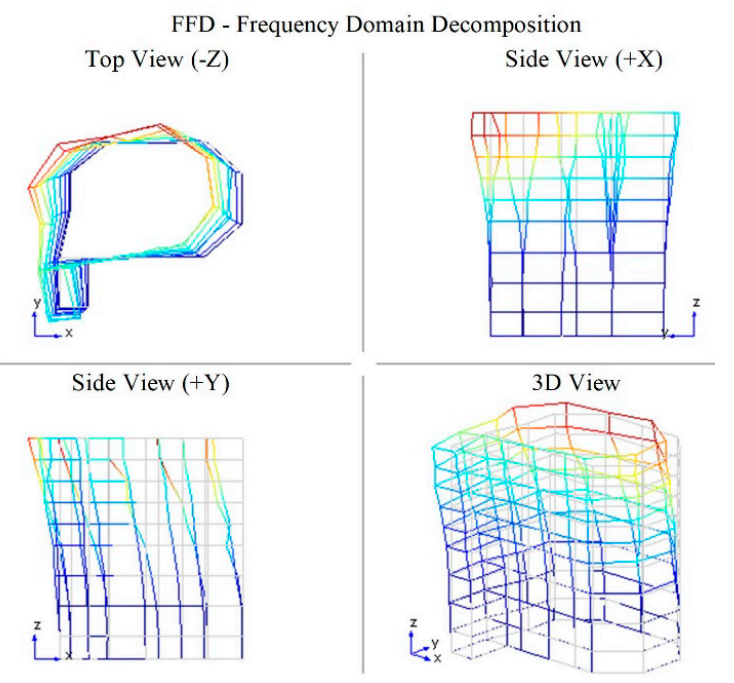

(b)

Figure 10. Cont. 


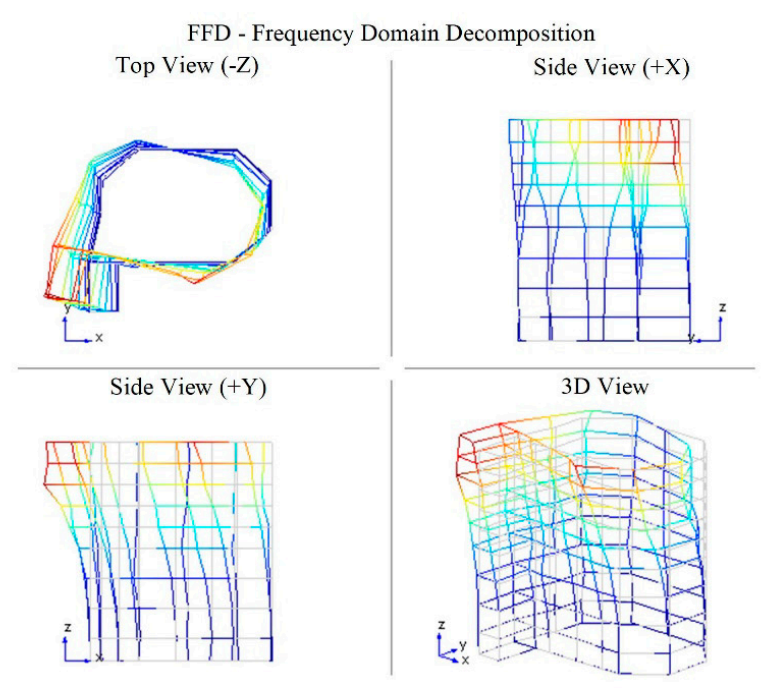

(c)

Figure 10. Modal shapes: (a) the first (eigenvalue $3.25 \mathrm{~Hz}$ ); (b) the second (eigenvalue $3.81 \mathrm{~Hz}$ ); (c) the third (eigenvalue $4.50 \mathrm{~Hz}$ ).

\subsection{Numerical Models and Analysis Methods}

Different numerical models with various levels of complexity were created using the finite element program package Etabs [43], with an emphasis on the identification of critical structural elements and capturing the failure mechanisms of the structure. The results obtained by the experimental testing of building structural dynamic parameters, as well as the measurements of underlying soil in order to estimate the ground type according to Eurocode 8 (EC8), were very important for the verification of the as-built state of the building and they were used for the calibration of the initial numerical model (Figure 11). This model was created on the basis of the collected building data and field surveys, with the stiffness of the structural elements corresponding to the stress state for a real vertical load. Depending on the observed limit state, different numerical models were additionally formed, including different participations of primary and secondary elements with the corresponding level of cracking.

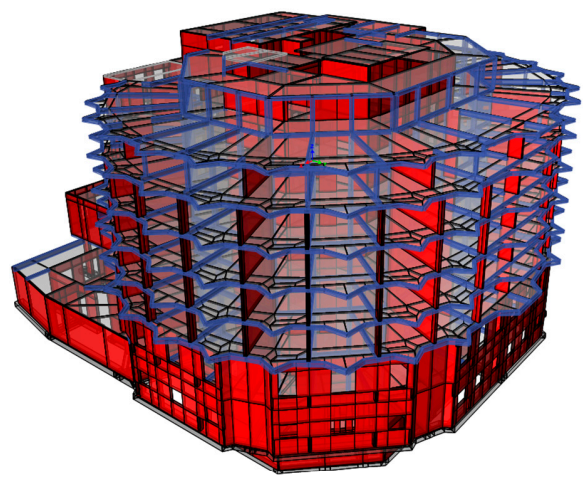

(a)

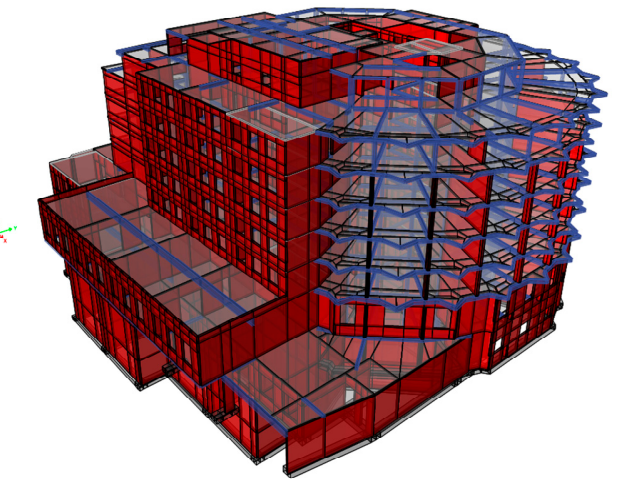

(b)

Figure 11. Numerical model of the structure: (a) south-east view; (b) north-west view.

Numerical models comprise a 3D beam (for columns and beams) and shell finite elements (for walls and slabs). Due to the size of the building, the complexity of the geometry and its irregularities in terms of the height and floor plan, the numerical model is extremely demanding for the computer calculation. It is worth mentioning that the numerical model has 661,400 degrees of freedom (DOFs). 
The cracking of the cross-sections during seismic loading was accounted for according to Eurocode [44] and American Society of Civil Engineers (ASCE) code [45]. Therefore, the element flexural stiffness was reduced to a $30 \%$ stiffness for uncracked elements for beams and slabs, while for columns and walls the reduced stiffness was 30\% to 50\% (depending on the axial force) for the uncracked elements. The beams were defined with the effective slab width. The shear stiffness of all elements was reduced to $40 \%$ of the initial stiffness of uncracked elements. The in-plane diaphragm action was assumed for floor slabs.

The nonlinear behavior of structural elements was taken into account by hinge models and fiber-type models. The choice of an appropriate model type involves a balance between reliability, practicality, and computational efficiency. The adoption of the model type for each element depends on the governing modes of behavior, the expected amount of nonlinearity, and the level of detail available for the input and output data. The reliability of the model comes from its ability to capture the critical types of deformation that are of interest to the modeler and control the response [46].

Concentrated plastic hinges account for the moment failure mechanisms for a level of axial and shear force or shear failure mechanisms for a specific axial force. This model is phenomenological and describes the structural behavior which is based on a calibration to the overall component behavior.

Fiber-type models, with a finite length hinge zone, behave according to given material diagram for mean material characteristics. Fiber-type models provide the capability to numerically integrate the material response through the member cross-sections. The behavior and characteristics of plastic hinges depend on more parameters, e.g., the level of axial and shear force is important for the ductility of flexural hinge. The element ductility was calculated on the basis of section dimensions and built-in reinforcements in the critical structural elements.

The force-deformation relations (capacity curves on Figure 12) for the structural elements and acceptance criteria for the performance requirements were defined in accordance with Eurocode 8-3 [44], but considered also the guidelines provided by National Institute of Standards and Technology (NIST) [46-48], Federal Emergency Management Agency (FEMA) [49-52] and ASCE [45] for the derivation of the cyclic backbone curves. Furthermore, guidelines [53] and scientific papers presenting the experimental testing of walls (e.g., [54-57]) were considered for squat walls, because of the unreliability of their failure mechanisms and ductility calculation. Large structural redundancy causes significant robustness, although failure mechanisms of primary elements are mostly non-ductile shear failures, which was taken into account during analyses.
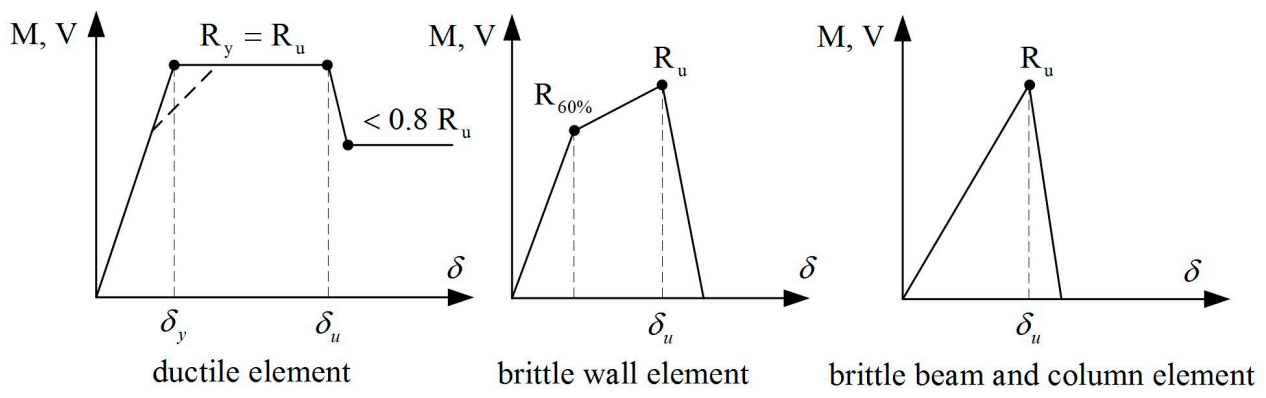

Figure 12. Typical force-deformation relation for concrete non-ductile elements.

The shear capacities of structural elements were calculated on the basis of the concrete strength and as-built reinforcement. Different design regulations $[44,45,58,59]$ were accounted for and critically compared, based on an engineering judgement. The capacity curves and acceptance criteria for lightly reinforced walls were also supplemented by experimental studies presented in [60,61]. The selected values were then used for the definition of the shear hinges. Column capacity to interaction of the moment and axial force was calculated according to the section characteristics. 
For nonlinear time-history analyses, the local nonlinear behavior of elements was defined using hysteretic capacity curves with loading and unloading branches (degradation of the material due to cyclic loading).

The vertical load was defined on the basis of the as-built structure and comprises the self-weight, additional dead loads from non-structural elements and $20 \%$ of the live load. A structural analysis for vertical loads is essential for further analyses (static or dynamic) and it is necessary to determine the internal forces and, generally, structural conditions before applying earthquake loading. The element stress state is directly linked to the stiffness and ductility of elements, and consequently their seismic performance. The level of axial force significantly affects the rotation and shear capacity of columns and walls. Because of the large number of data and model complexity, the results for vertical load will not be presented in the paper.

The following methods were applied in the seismic analysis of the hospital building: a lateral force analysis (linear) according to the first vibration mode, modal response spectrum analysis (horizontal elastic and design), nonlinear static (pushover) analysis, accounting for three different load patterns, and nonlinear time-history (dynamic) analysis, using synthetic accelerograms.

The first performed analysis was the lateral force analysis according to the first vibration mode of the cracked structure, although the building does not comply with all the necessary conditions for applying this method according to valid regulations, because it is irregular in terms of its height and plan. However, this method was used in the original seismic design, so it should have been accounted for. The second method applied was the modal response spectrum method, with the assumption of linearly elastic structural behavior, using uncracked and cracked sections. The structure was considered as non-ductile in calculations (DCL) and a behavior factor of $\mathrm{q}=1.5$ was used.

The pushover method was applied with three load patterns tested on this building: a uniform pattern, triangular pattern (linearly varying in height) and modal pattern, taking into account the first modal shape in the considered direction. The calculation was performed by using the static method, using displacement control. Material nonlinearity was accounted for in the analysis, while geometric nonlinearity was not, because it was shown that this effect was minor due to the building stiffness and small displacements at failure. Modeling approaches and techniques suitable for pushover analyses of RC structural wall buildings, presented in [18,62], were also considered. The procedure for the determination of the target displacement using an equivalent single degree of freedom (SDOF) model was not performed, because the elements fail mostly because of their brittle mechanism, redistributing loads to adjoining elements. Moreover, it is unreliable to reduce such a complex and irregular building to SDOF.

Nonlinear time-history analyses were performed using accelerograms generated for different earthquake scenarios, as described before. For every level of earthquake intensity (linked to the return period), sets of accelerograms in orthogonal directions were applied (artificial accelerograms and simulated accelerograms based on a deterministic earthquake scenario). However, the results in the following chapter will be presented only for three representative sets per intensity, because of the simplicity and transparency of the display. Two approaches for generating the accelerograms have already been described, but it should be pointed out that while the approach with accelerograms matched to target spectra is more conservative and will cause lower values of the building load-bearing capacity, the more realistic hazard is obtained using the second approach.

\section{Results}

As already discussed in the previous chapter, a very large output was obtained. Therefore, only the most important results will be presented herein, with the focus on nonlinear analyses. The building assessment includes the displacement (absolute and relative) verification, capacity verification and verification of local ductility of critical structural elements. Depending on the complexity level, potential failure mechanisms due to earthquake loading are presented, and critical elements 
identified, which may be of great importance for proposing retrofit measures and facilitating post-earthquake procedures.

\subsection{Dynamic Properties of the Building}

The building is irregular in plan and in height, which is very unfavorable for its dynamic response. High torsional effects occur due to eccentricities of the mass and stiffness centers on every story. Therefore, large demands are imposed on displacements of structural columns and walls near the edge of the structure. Irregularity in height causes variabilities in inter-story drifts. The structure comprises primary (seismic) and secondary elements. Primary elements resist vertical and horizontal loads (mostly walls, with small contributions from the frame system near the building edge), while it is assumed that secondary elements may fail due to earthquake loading, but the structure or part of the structure will not lose its load-bearing capacity for vertical loads. Depending on the failure mechanism and structural layout, some coupled beams and beams are considered as secondary elements, as long as their failure does not induce the collapse of the slab above. Moreover, some columns in the plane of the wall system are also considered as secondary elements. As structural walls are mostly squat, the system is very stiff and does not have a high capacity of energy dissipation in the inelastic range. Therefore, its ductility capacity is also limited. However, the area of walls in relation to the floor area is large, so the redundancy and robustness of the structure are high. It has been confirmed by analysis that a redistribution of forces to adjoining elements occurs after the cracking of critical structural elements, thus, avoiding failures and collapses of parts of the structure. Hence, the system possesses capacity reserves, though limited by inter-story drifts. Partition walls participate in the structural response for the low amplitude excitations. However, for high excitations, it may be expected that, because of their discrete connections (anchors), they will not contribute to stiffness, but only to the mass in structural responses. Since these elements are mostly connected to the floor system, a significant contribution to lateral load-bearing systems cannot be expected.

The first phase of numerical modeling was adjusted for ambient vibrations because of the model calibration, in order to confirm the geometric and initial material data of the building. This model has limited capability of cracking because it is loaded only with a dead and partially live load. Following Figure 13 presents three-dimensional views (perspective, view from above and side view) of the structural vibration modes for the initial model.

Comparison of the numerically obtained dynamic properties with experimentally determined properties confirms the validity of the initial numerical model. The first mode is mostly the translation in direction $\mathrm{Y}$, while the second and the third correspond to a translation in the $\mathrm{X}$ direction coupled with torsion.

In addition, the second model was created and showed the significantly damaged state of the cracked elements due to earthquake action. The periods and modes of vibration of the structure were calculated and the values $0.571,0.448$ and $0.323 \mathrm{~s}$ for the first three modes were obtained.

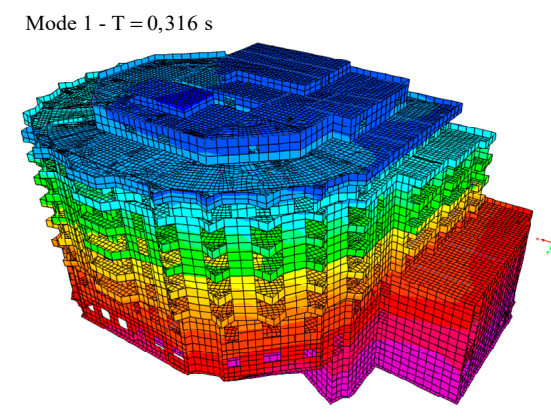

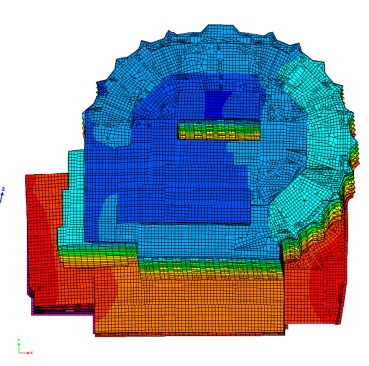

(a)

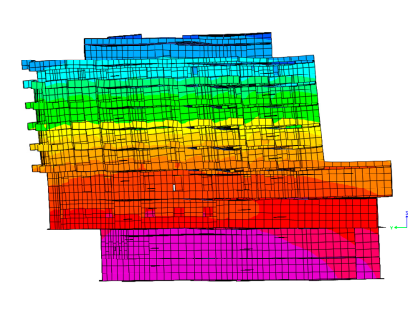

Figure 13. Cont. 

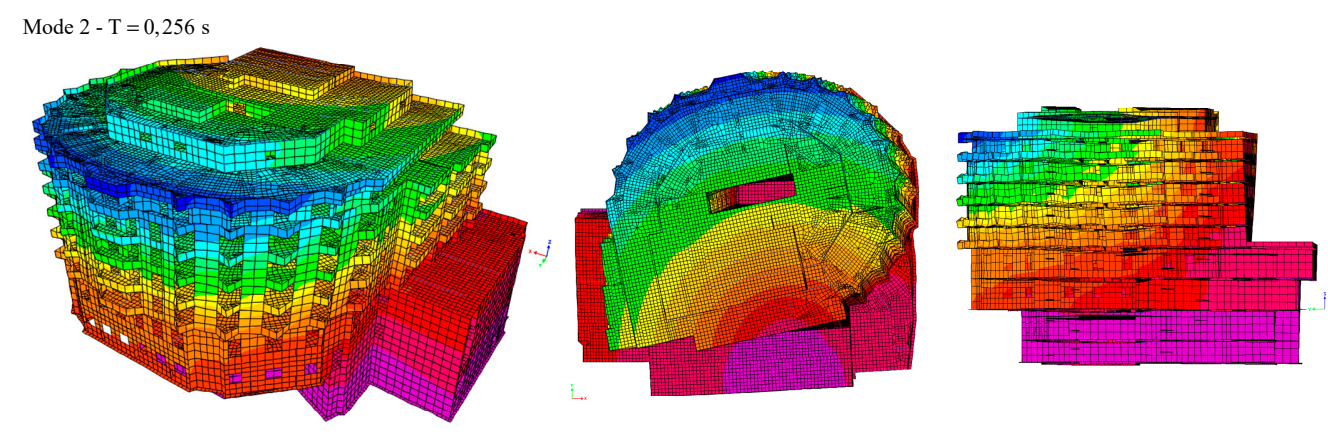

(b)
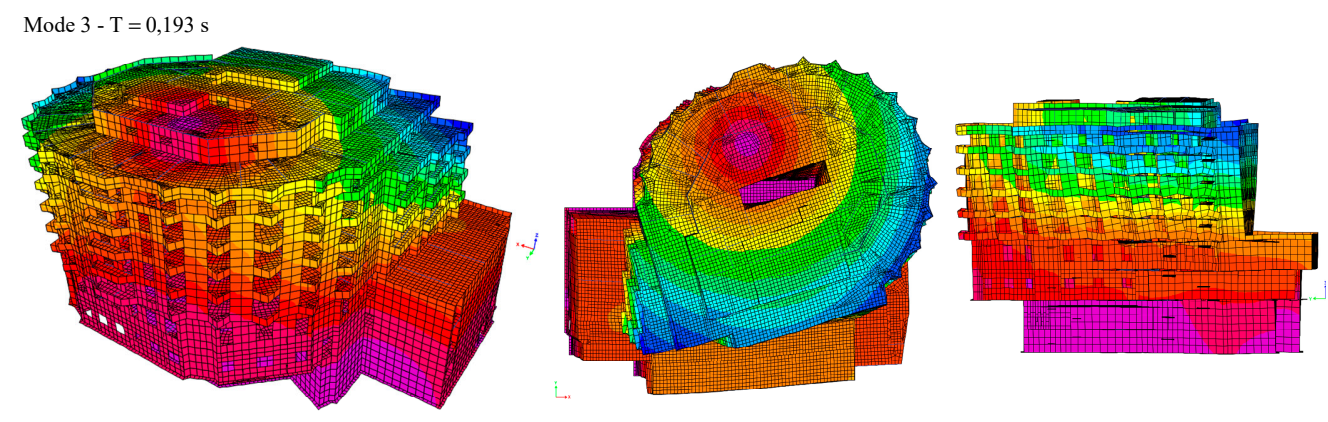

(c)

Figure 13. Three-dimensional view of mode shapes of the initial numerical model: (a) first; (b) second; (c) third.

\subsection{Linear Analysis: Lateral Force Method and Response Spectrum Method}

A preliminary analysis was conducted for seismic loading calculated in the original seismic design, using the lateral force method and accounting for the assumptions on the building importance and seismic zone. Lateral forces act only on the building part above ground level. This assumption was verified later by detailed seismic analyses. Moreover, the linear distribution of forces along the height was assumed, which was shown to be a governing load pattern in the nonlinear pushover analyses performed after. It can be stated that the seismic base shear force of the building, according to the original seismic design, is approximately equivalent to the shear force according to Eurocode 8, with ag $=0.15 \mathrm{~g}$.

The cracking of structural elements was accounted for, as it was assumed that the structure will reach a significantly damaged state. Only story shears are presented in the following figure (Figure 14), because this analysis method is only a referent point for the more complex analyses.

Ratios of the base shear to vertical loading and average story shear stresses were calculated for the critical stories three (ground floor) and five (third story above ground level). Base shear ratios in story three amount to $12 \%$ for the $X$ and $Y$ directions, while in story five these values are $18.7 \%$ for the $X$ and $Y$ directions. It may be observed that the base shear ratios are larger for story five (third story above ground level) than for story three (ground floor), and that the average shear stresses in the $Y$ direction are higher than in the $X$ direction, due to the lower total wall area. The average shear stress amounts to 0.48 and $0.73 \mathrm{MPa}$ for directions $\mathrm{X}$ and $\mathrm{Y}$ at story five, while at story three these stresses are 0.32 and $0.37 \mathrm{MPa}$ for directions $\mathrm{X}$ and $\mathrm{Y}$. It should be emphasized that the average shear stress in a story may only be used for the preliminary assessment of the stress level in walls, because the building plan is very irregular and the walls are not uniformly distributed. A moderate level of compression stresses in the walls at stories three and five is favorable and increases the allowable stress levels. However, due to plan irregularity and the very uneven distribution of walls, tension stresses in walls may occur along the edge. 


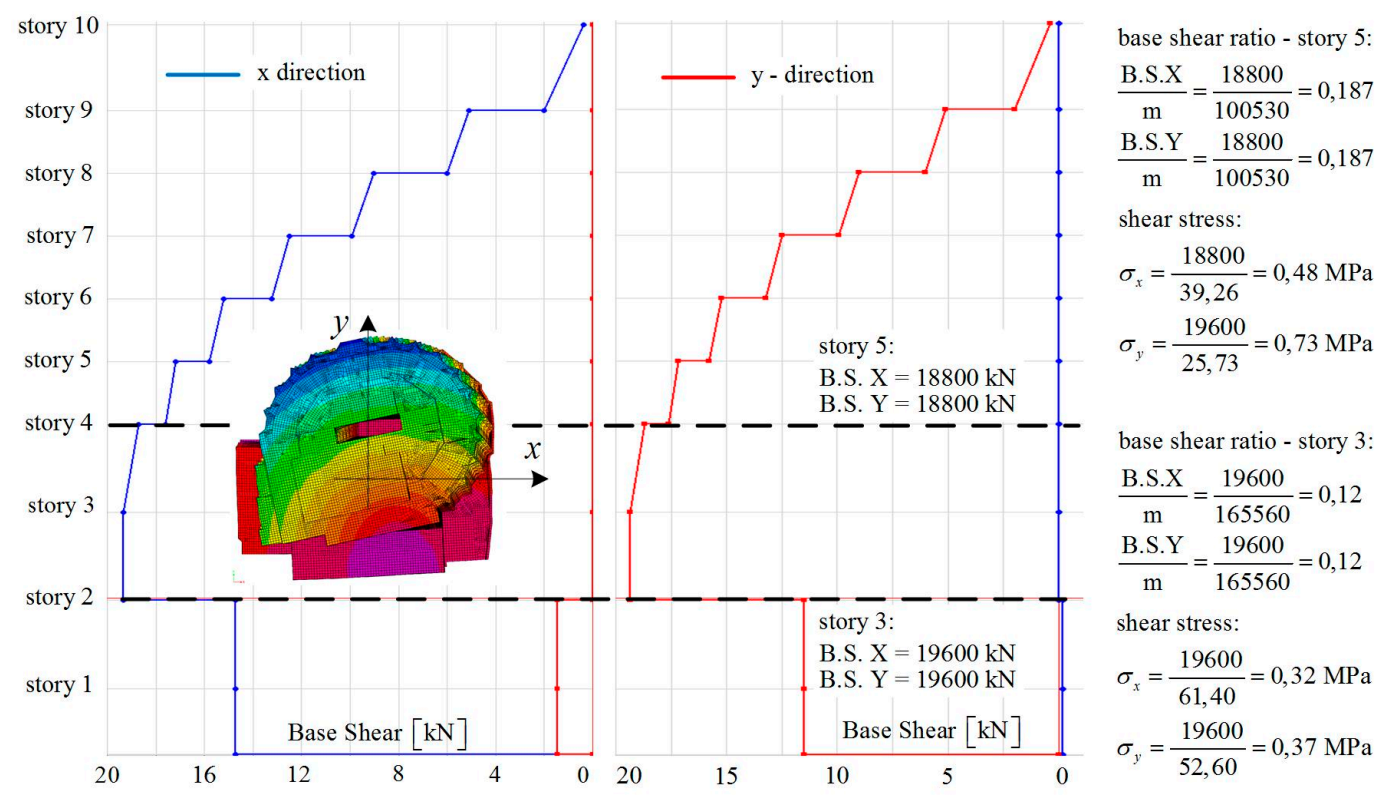

Figure 14. Story shears for the lateral force method applied in the $X$ and $Y$ directions.

Response spectrum analysis was conducted in accordance with valid seismic regulation, using the design response spectra for the 95 and 475 year return periods. The importance factor was not accounted for, although for a building of such importance the value of 1.4 should have been used. This decision was made in order to enable a comparison of the structural response to earthquake loading defined within different analysis methods. Generally, an importance factor is used to analyze buildings for earthquakes of a larger return period. All other assumptions were accounted according to Eurocode 8 . An eccentricity of $5 \%$ was taken into account and the behavior factor was defined as 1.5 , because of primary non-ductile failure mechanisms and a lack of transversal reinforcement. The cracked state of the cross-sections was taken into account, as it may be assumed that the structure will reach a state of significant damage. The story shears for the design response spectra for 475 years return periods are presented in Figure 15.

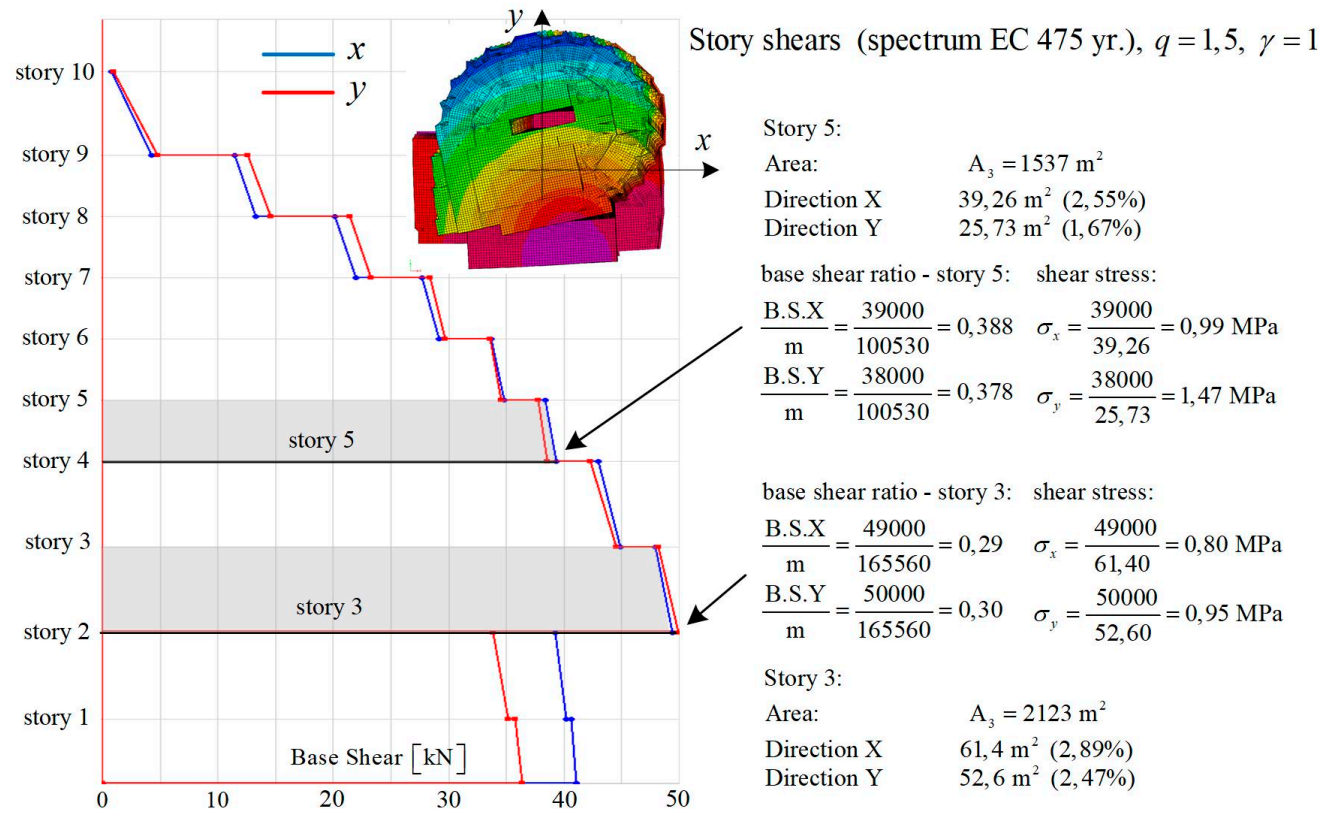

Figure 15. Story shears in directions $\mathrm{X}$ and $\mathrm{Y}$ for the design response spectrum case (return period (RP) 475 years). 
Ratios of the required to as-built reinforcement in critical structural elements at stories three and five are presented in Figure 16, so critical locations may be identified. As previously mentioned, minimal reinforcements in elements according to the valid code differs from the original code, so particular elements do not comply with modern regulations. The failure of many components accounting for the Eurocode requirements may be observed. At both stories there are many walls in which the ratios of the required to as-built reinforcement exceed $200 \%$, so it may be concluded that as-built reinforcements mostly do not comply with the requirements of Eurocode 8, for resisting horizontal loads defined by the prescribed response spectrum case.
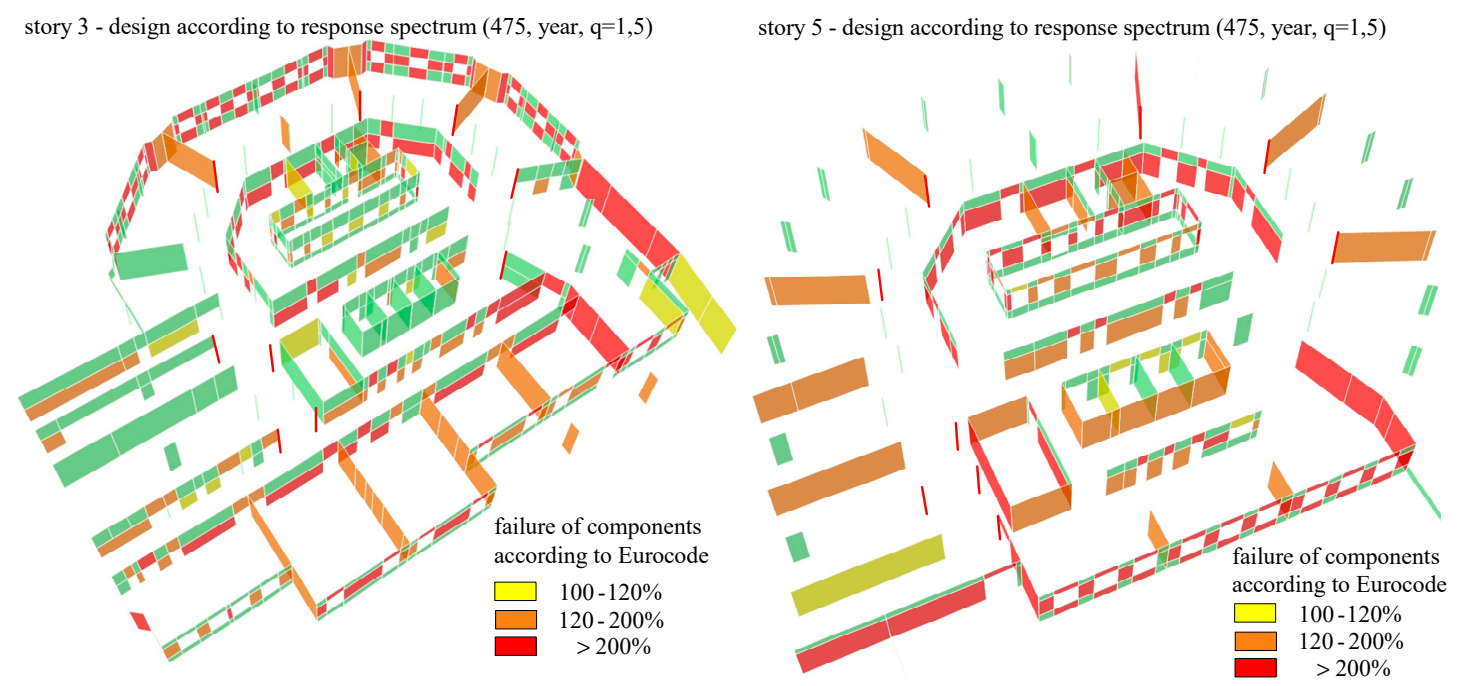

Figure 16. Critical structural elements at stories 3 (ground floor) and 5 (third story above ground level for design response spectrum case (RP 475 years).

\subsection{Nonlinear Static Method (Pushover)}

A pushover analysis was performed and verified for different horizontal load patterns, but only the most important results for determining the total lateral capacity of the structure will be presented. The pushover curves were determined separately for every horizontal direction, accounting for both positive and negative directions of the loading. However, an important requirement for the application of this method is that the structure mainly responds in its first vibration mode. Taking eccentricity into account was necessary because the structure is not symmetrical in plan and it is subjected to significant torsional effects. Additionally, mean values of material properties were used in the structural model.

As previously mentioned in the method description, the procedure for the determination of the target displacement using an equivalent SDOF model was not performed, because the structure fails with a minimal yielding of structural elements and is mostly in brittle mechanisms, transferring loads to adjoining elements. Therefore, specific points on the pushover curves were analyzed, and the redistribution of forces in the story structural elements was checked. This procedure enables the detection of the mechanism's development and failure of the structure. Firstly, the influence of torsion depending on the direction of loading was analyzed, obtained using different horizontal load patterns (uniform, triangle and modal patterns, taking into account the first modal shape in the considered direction). Two points on the building top located at different sides of the wall core were considered. When comparing the pushover curves obtained using the displacements of these two points, it was observed that torsional effects are significant for loading in $\mathrm{X}$ direction, while the effects for the $\mathrm{Y}$ direction are not (curves are similar). This might have been expected, as the first vibrational mode was the translation in the $\mathrm{Y}$ direction, while the second one was the translation in the $\mathrm{X}$ direction, coupled with torsion. The pushover curve obtained using the triangular load pattern was chosen as the representative one and therefore, following Figures 17 and 18, correspond to this load pattern. 
These figures show representative and envelope pushover curves (base shear vs. displacement), for positive $X$ and $Y$ directions, with marked characteristic points of the structural state corresponding to the particular level of load (black dot for the original curve and the red one for the envelope curve). The scheme of story five with depicted critical structural elements is given for every structural state in order to gain insight into the damage level associated with a particular level of load. The base shear according to the original seismic design was defined as the reference value.

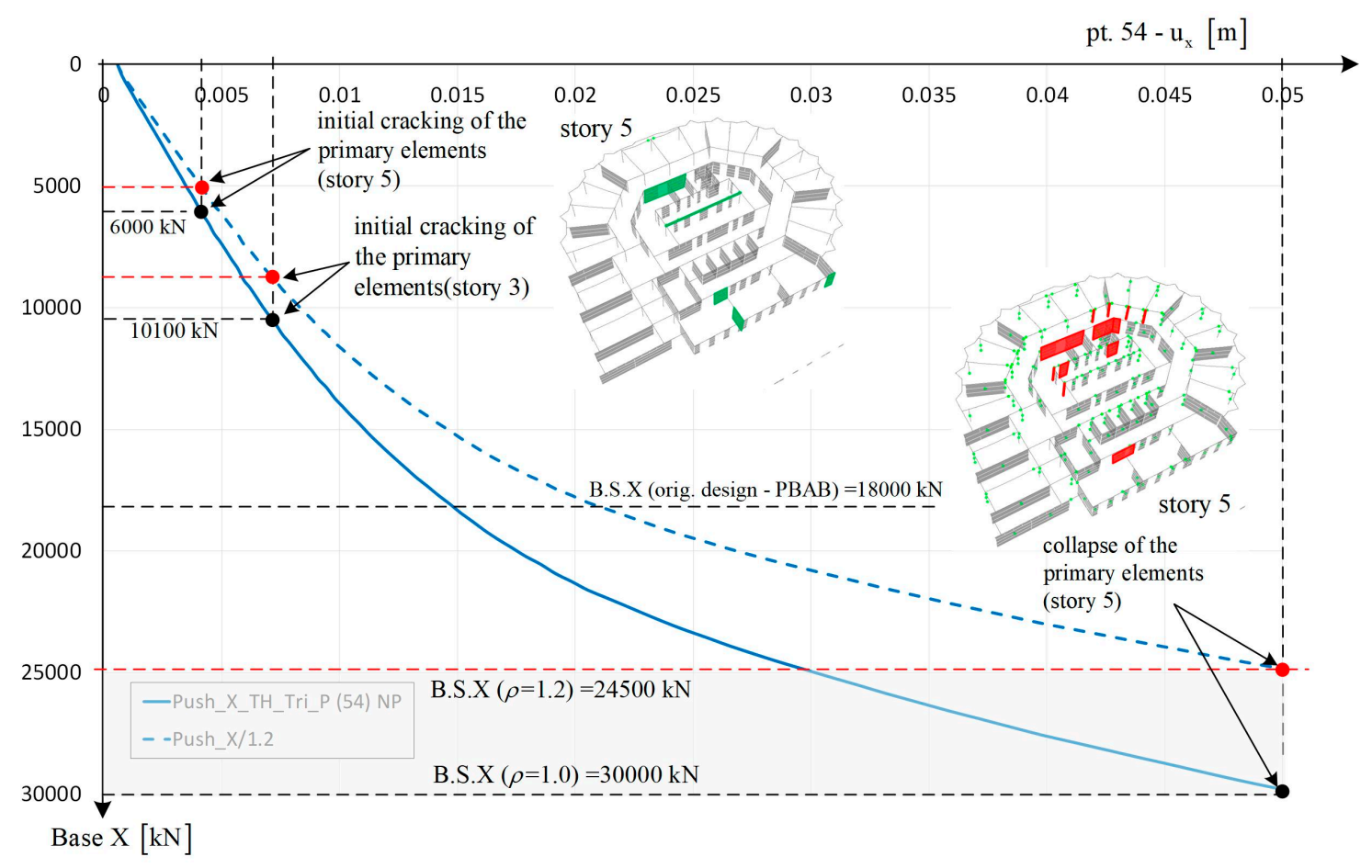

Figure 17. Pushover curve for the triangular load-pattern and envelope curve (base shear X vs. the displacement of point 54).

The sensitivity analysis of the input parameter variation was conducted in a limited form due to the extreme complexity of the model and the duration of the calculation. The expected variation in load-bearing parameters caused a change in the global response of the structure of approximately $20 \%$. Accordingly, the pushover curve was reduced and the lower bound of capacity determined, as presented in the figures below.

For the $\mathrm{X}$ direction, it may be observed that particular structural elements reach inelastic regions very fast, which is visible on the pushover curve as stiffness reduction (slope of the curve). The initial cracking and reduction of stiffness in some elements occur already under $6000 \mathrm{kN}$ of force $(3.7 \%$ base shear coefficient). Taking into account safety margins, this value would be $5000 \mathrm{kN}(3.1 \%)$. These elements are shown on the scheme of story five on the right side of the curve. It is important to note that this does not necessarily mean that these elements lose their capacity/fail, but the force they resist exceeds $60 \%$ of their capacity and the cracking occurs. The next characteristic point is associated with failures of some main structural components, which may lead to a partial collapse of the structure. As depicted in the figure, critical elements are marked with a red color. Failure occurs for the force amounting to $30,000 \mathrm{kN}(19 \%)$, or $24,500 \mathrm{kN}(15 \%)$, taking into account the safety margins (Figure 19a). The mechanism is a brittle failure of columns and walls at story five, mostly on the south-western building part, triggered by torsional effects (torsion was accounted for in the horizontal load-pattern in the pushover analysis). Consequently, local slab failures may occur. However, even if that happened, the rest of the structure will not collapse for this level of force. 


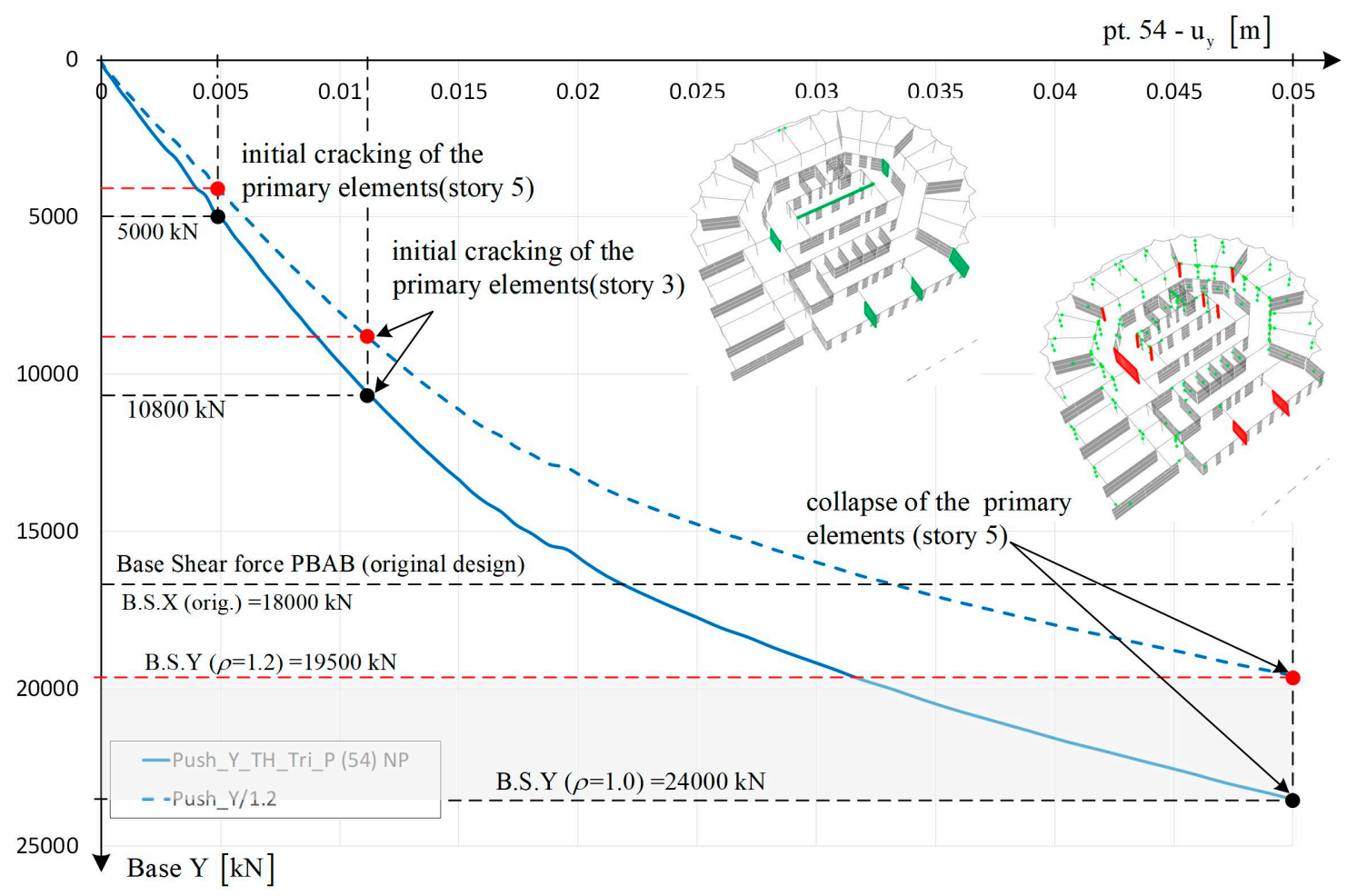

Figure 18. Pushover curve (base shear $Y$ vs. the displacement of point 54) with marked important points associated with the specific structural performance.

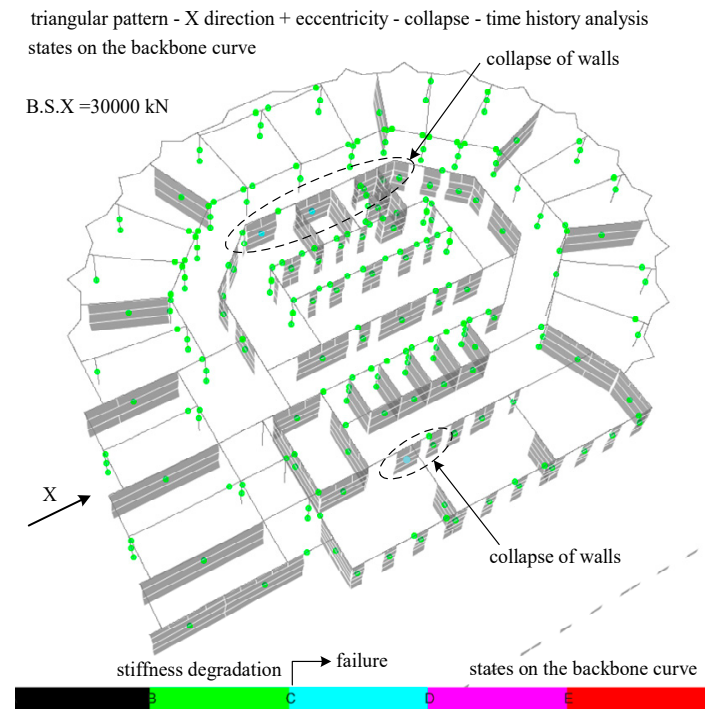

(a)

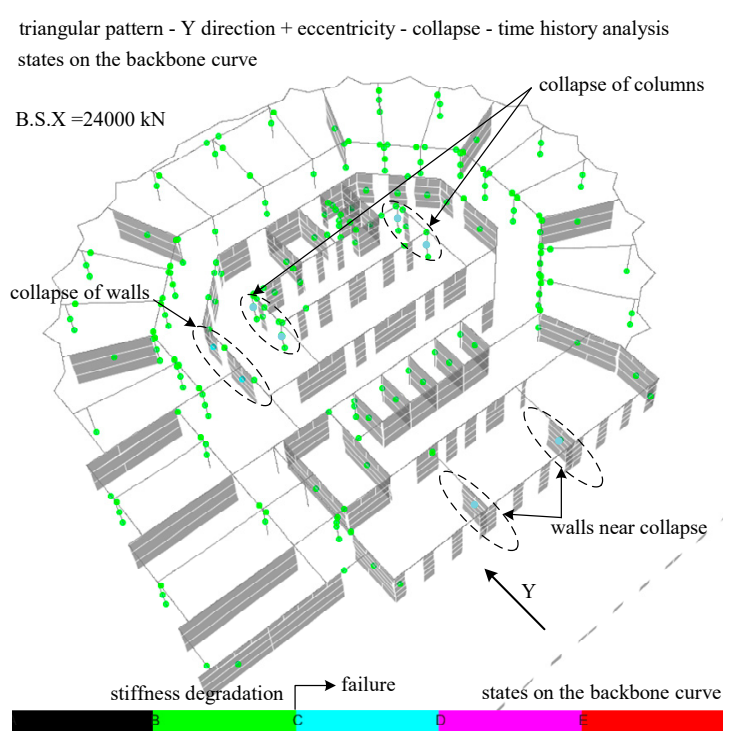

(b)

Figure 19. Structural system at story 5 for the near-collapse state: (a) pushover X; (b) pushover Y.

For the $\mathrm{Y}$ direction, it may be observed that the initial cracking and reduction of stiffness in some elements occur already for a $5000 \mathrm{kN}$ force (3.1\% base shear coefficient). Taking into account the safety margins, this value would be $4000 \mathrm{kN}(2.5 \%)$. These elements are shown in the scheme of story five on the right side of the curve. Failures of critical elements and a partial collapse of the structure occurs for the force level of $24,000 \mathrm{kN}(15 \%)$, or 19,500 (12\%), taking into account the safety margins (Figure 19b). The critical elements are marked with a red color. Unlike the $\mathrm{X}$ direction, there are no significant torsional effects and the distribution of forces is relatively uniform, which contributes to the increase in the lateral capacity for earthquake loading in the $\mathrm{Y}$ direction. However, there are fewer 
walls constructed in this direction, so the level of force that the structure may resist is similar in both directions (direction $X-16,300 \mathrm{kN}$, direction $\mathrm{Y}-19,500 \mathrm{kN}$ ). The advantage of the structural system comprising many lightly reinforced walls should also be pointed out. Its high static indeterminacy provides capacity reserves, so it may be assumed that collapses would be localized and not spread to a larger area.

The following figures present the condition of the structural elements for the near-collapse state of some primary structural elements.

\subsection{Nonlinear Time-History Analysis}

The results obtained by time-history analysis, due to seismic loading for various intensities depending on the earthquake return periods, will be presented in the following text. Sets of acceleration records, obtained by two different approaches (Section 3.3), with a peak ground acceleration on the bedrock of $0.16 \mathrm{~g}$ for 95 year RP and $0.302 \mathrm{~g}$ for 475 year RP, were used in analysis. The prescribed requirements and limit states in Eurocode 8-3 [43] correspond to defined earthquake return periods. Although the records were generated also for the 2475 year RP, the analysis has shown that this level of earthquake intensity is too high for this building, so the results are not presented herein.

Artificial records, matched in the frequency region to be compatible with the target response spectra, are labelled EC8, while the records representing the deterministic seismic hazard of the hospital location are labelled OBDD.

Only the most significant results, comprising two sets of accelerograms per one return period, are presented, due to a large amount of obtained data. It is important to note that the presented results are representative for all time-history analyses performed at that particular earthquake intensity.

Failure mechanisms and the behavior of critical structural elements will be qualitatively and quantitatively depicted. The base shear and horizontal displacements of the control point near the building top (at story nine) are presented as fundamental structural response parameters. In addition to the characteristic point, displacements of the point located at the same story, but on the opposite side of plan, are shown. By comparing displacement responses, torsional effect in the structural response may be observed. Furthermore, shear forces in critical structural elements are presented because it was confirmed that failure in most of the elements is induced by shear.

Critical structural elements and control points (labels) at story five-the critical story for determining the structural seismic performance and the story where initial failures occur-are presented in Figure 20.

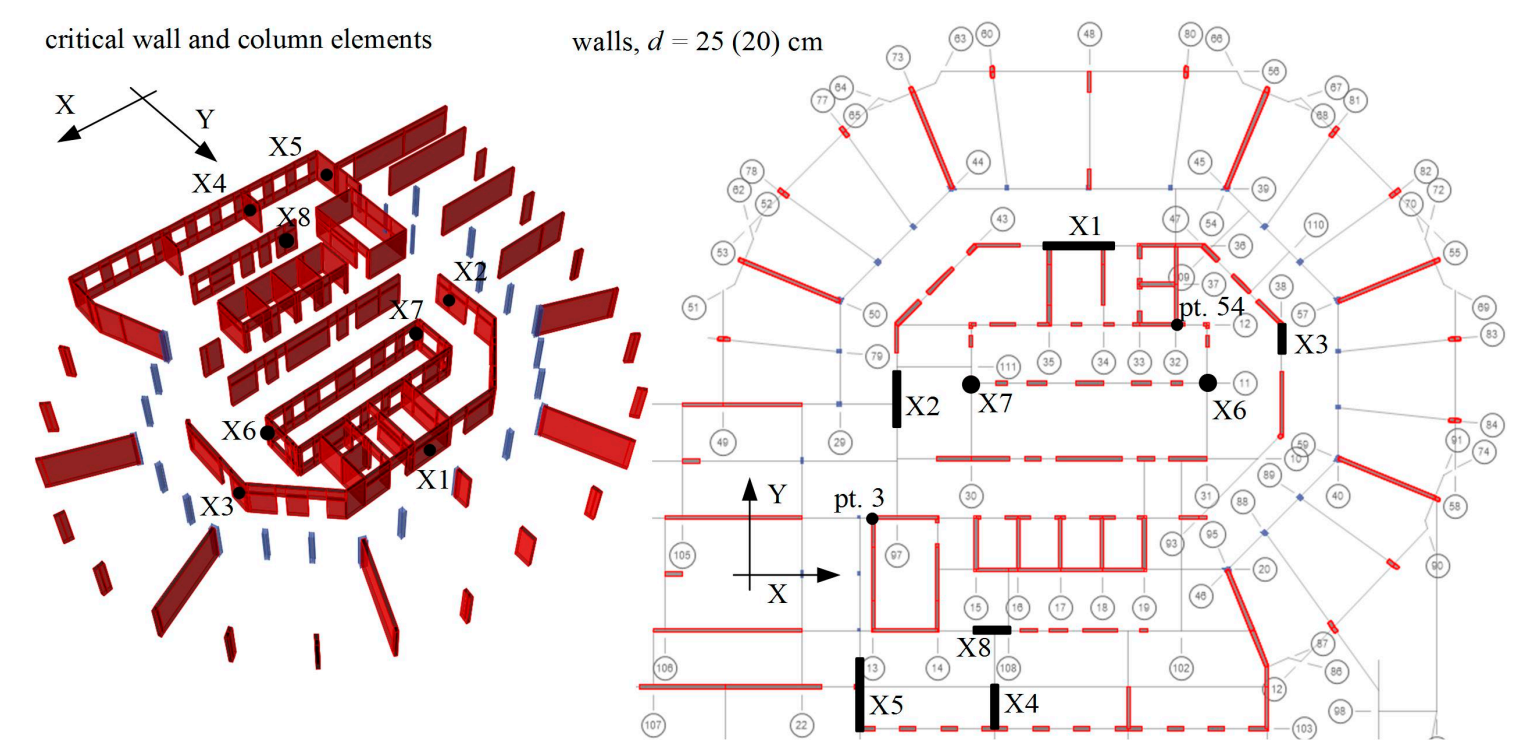

Figure 20. Story 5: critical structural elements (labels). 
In the following figures, the representative results are presented for six earthquake scenarios, calculated using a set of accelerograms:

- $\quad$ simulated for the location within the deterministic earthquake scenario of a 95 year RP with a PGA of $0.16 \mathrm{~g}$ (Figure 21);

- $\quad$ generated according to the Eurocode 8 spectrum for a 95 year RP with a PGA of $0.16 \mathrm{~g}$ (Figure 22);

- simulated for the location within the deterministic earthquake scenario of a 225 year RP with a PGA of $0.21 \mathrm{~g}$ (Figure 23);

- generated according to Eurocode 8 spectrum for a 225 year RP with a PGA of $0.21 \mathrm{~g}$ (Figure 24);

- simulated for the location within the deterministic earthquake scenario of a 475 year RP with a PGA of $0.30 \mathrm{~g}$ (Figure 25);

- generated according to Eurocode 8 spectrum for a 475 year RP with a PGA of 0.30g (Figure 26).

These figures show: (a) displacements of ux and uy of points 3 and 54 at story nine in time; (b) the base shear in the $X$ and $Y$ directions in time; (c) and (d) the shear forces in time for critical structural elements at story five; optionally (e) time snapshots of the failure mechanisms' development at story five.

In order to make the presentation of the results clearer, the diagrams show the first $10 \mathrm{~s}$ of the response in which the most significant part of the earthquake motion is realized.

For the deterministic earthquake scenario (95 year RP), it may be observed that the largest displacements amount to $2.0 \mathrm{~cm}$. The peak base shear is approximately $20,000 \mathrm{kN}$. Cracking and yielding of the critical elements occur, but the failure is not expected.

For the earthquake scenario (95 year RP according to the Eurocode 8 spectrum), it may be observed that the largest displacements amount to $3.2 \mathrm{~cm}$. The peak base shear is approximately $22,000 \mathrm{kN}$ (disregarding one particular peak), which corresponds to the value obtained by the response spectrum analysis. The cracking and yielding of the critical elements occur very fast. Furthermore, the number of yielding cycles is higher than in the case of the deterministic scenario accelerogram for the same PGA, so a significant degradation of some primary components may be expected, but due to the redundancy and robustness of the structure the failure is not expected.

For the deterministic earthquake scenario ( 225 year $\mathrm{RP}$ ), the largest displacements amount to approximately $2.5 \mathrm{~cm}$, while the peak base shear is $29,000 \mathrm{kN}$. Cracking of the critical elements occurs and cyclic loading will further reduce element ductility, so significant damage of the components may occur but the failure of the structural part is not expected.

For the earthquake scenario ( 225 year RP according to the Eurocode 8 spectrum) it may be observed that the largest displacements amount to $4.5 \mathrm{~cm}$, while the peak base shear is $30,000 \mathrm{kN}$. Critical elements start to yield but they possess a certain deformation capacity, so sudden failures should not occur. However, cyclic loading will further reduce element ductility.

For the deterministic earthquake scenario ( 475 year RP), it may be observed that after $2.5 \mathrm{~s}$ the nonlinear algorithm no longer converged and the analysis stopped, thus a partial collapse was reached. The peak base shear is $40,000 \mathrm{kN}$. It may be observed that the cracking and yielding of the critical elements occur very fast, followed by failures of particular structural elements.

For the earthquake scenario (475 year RP according to the Eurocode 8 spectrum), the nonlinear algorithm no longer converged and a partial collapse was reached. The peak base shear is $37,000 \mathrm{kN}$. Failure of some structural elements occurs which it is not necessarily associated with the total collapse of the building, but it points to the development of the local mechanism causing a partial collapse.

From the presented analyses it can be noticed that the accelerograms generated according to the Eurocode 8 spectrum are significantly less favorable for structural responses than the deterministic earthquake scenarios. 


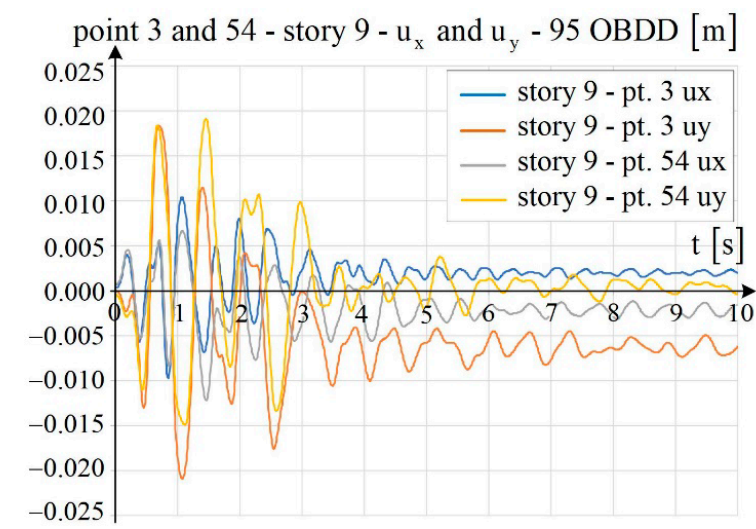

(a)

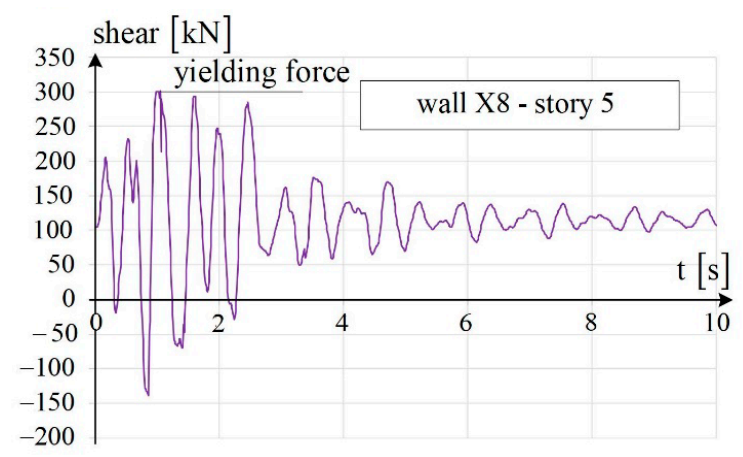

(c)
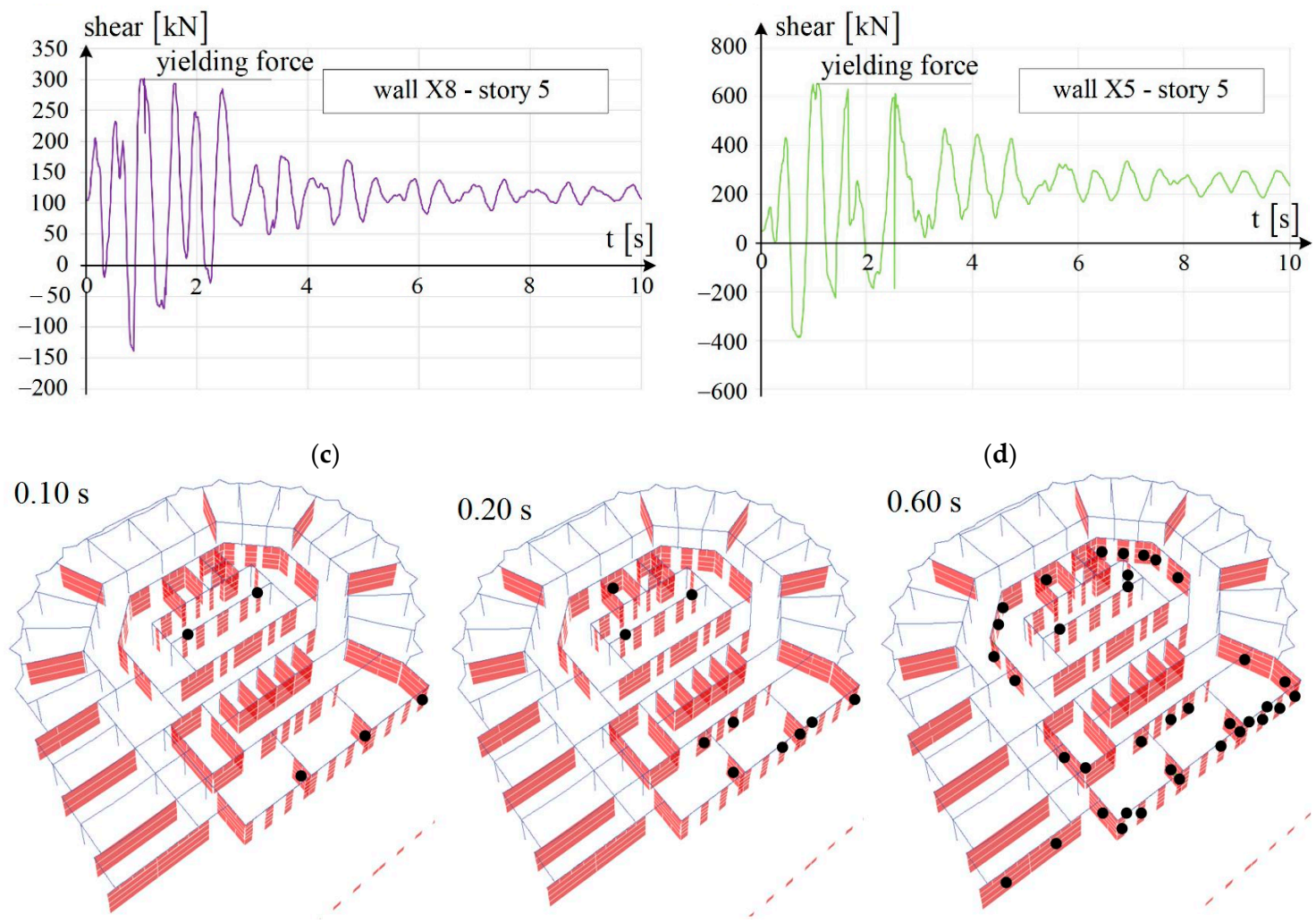

(d)

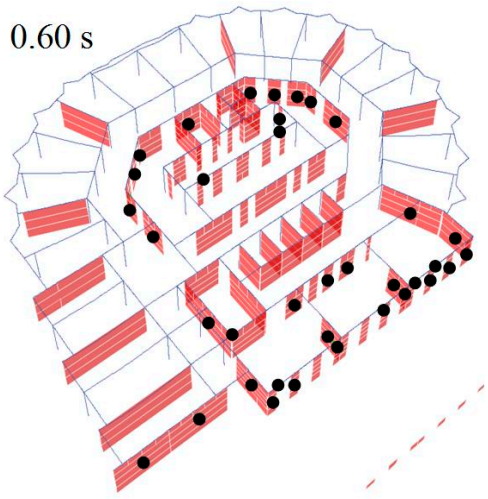

(e)

Figure 21. Earthquake scenario for 95 y RP-OBDD: (a) top displacements ux and uy (points 3 and 54 at story 9); (b) base shear in the $X$ and $Y$ directions; (c) shear forces in wall X8; (d) shear forces in wall X5; (e) time snapshots of failure mechanisms' development at story 5 . 


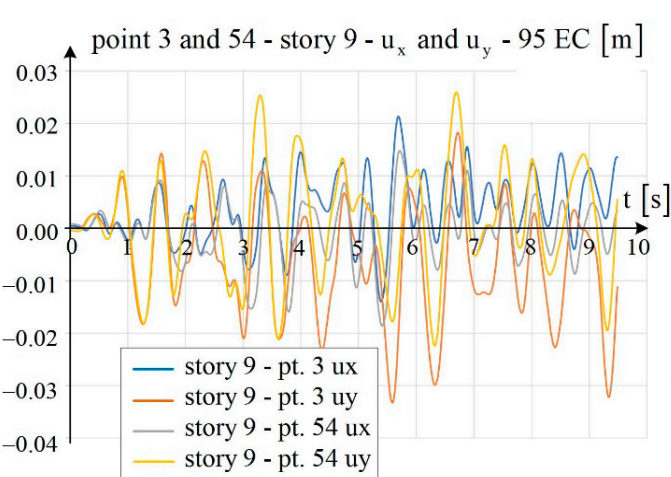

(a)

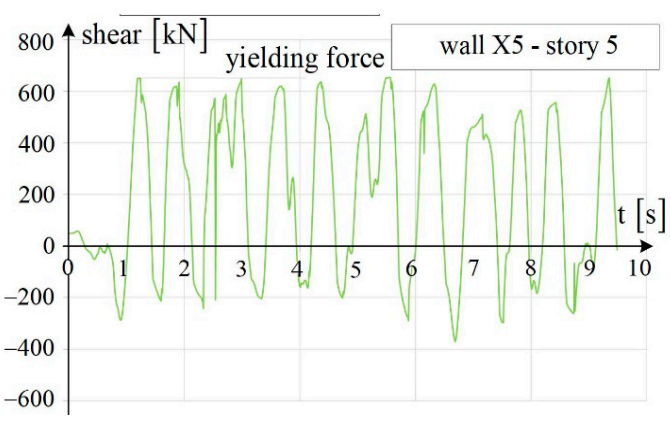

(c)

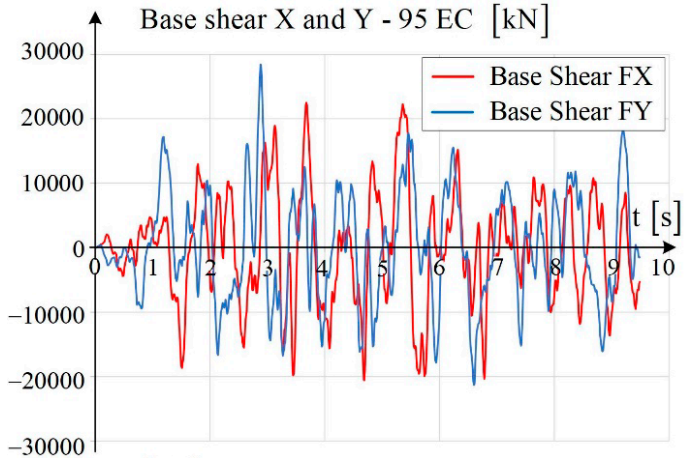

(b)

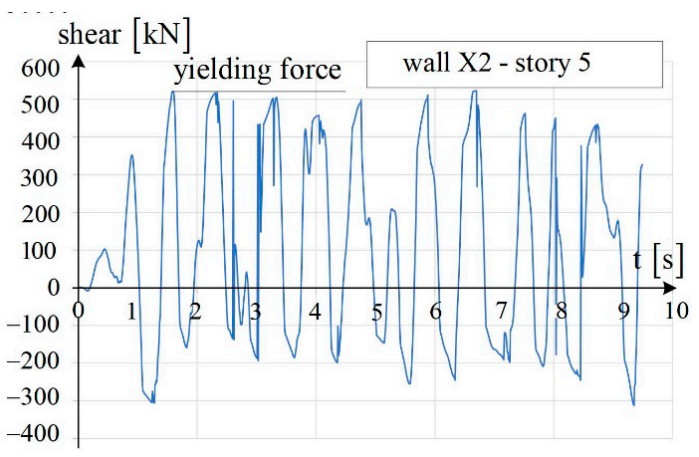

(d)

Figure 22. Earthquake scenario for 95 y RP-EC8: (a) top displacements ux and uy (points 3 and 54 at story 9); (b) base shear in the X and Y directions; (c) shear forces in wall X5; (d) shear forces in wall X2.

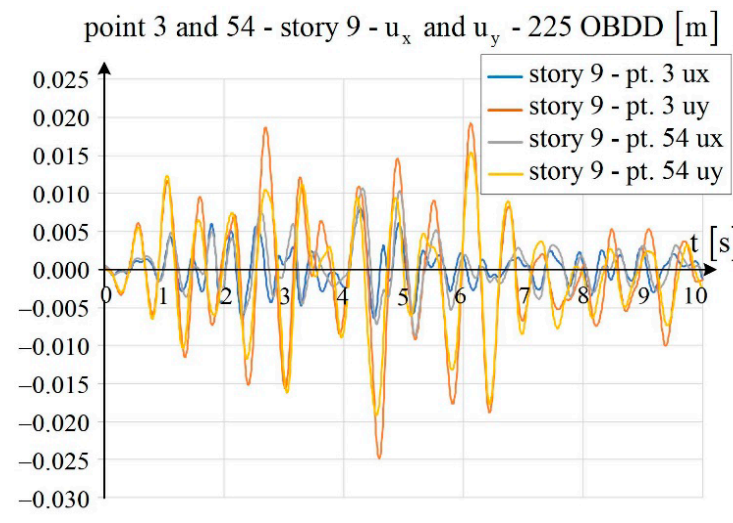

(a)

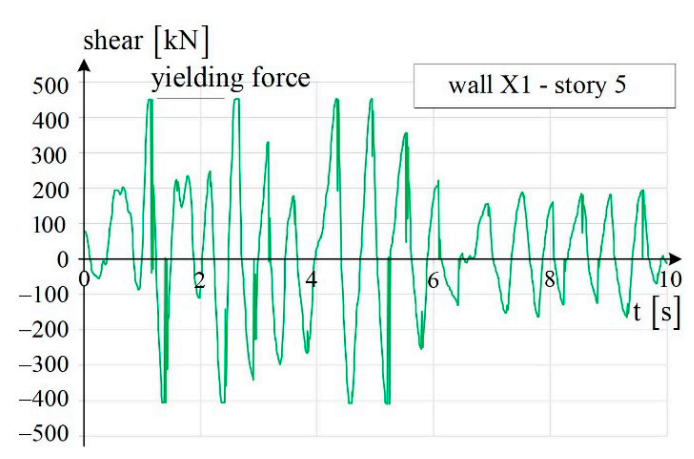

(c)

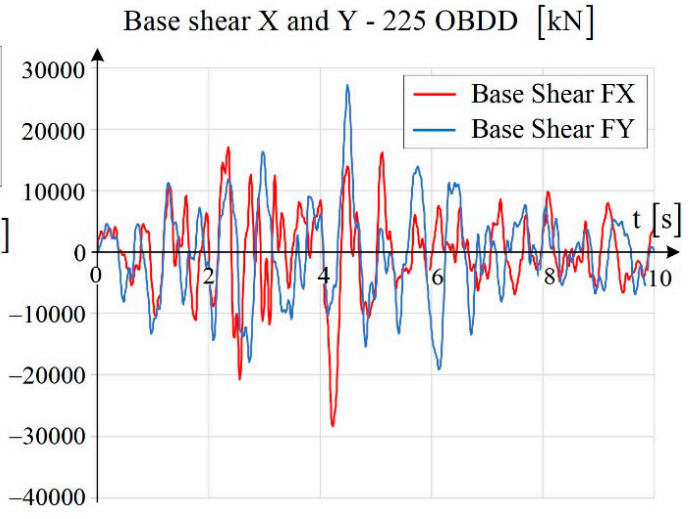

(b)

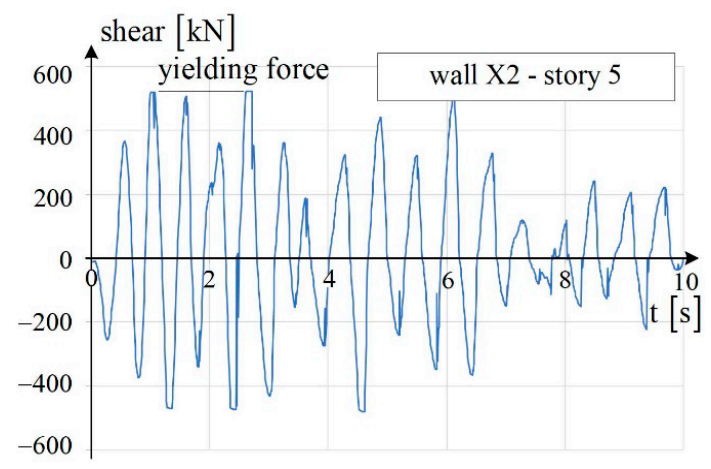

(d)

Figure 23. Cont. 

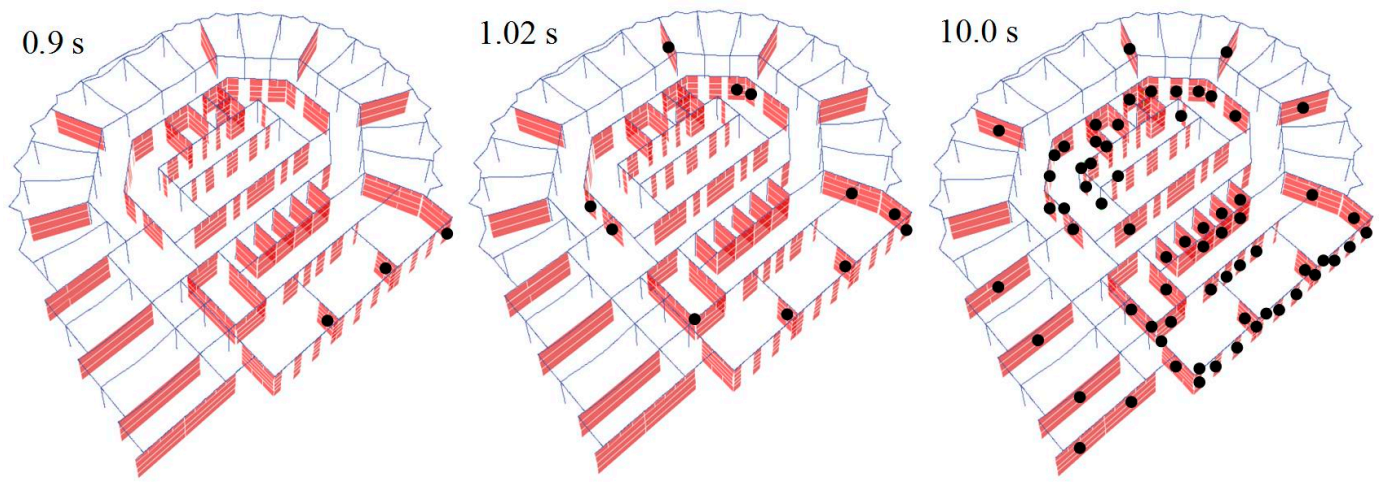

(e)

Figure 23. Earthquake scenario for 225 y RP-OBDD: (a) top displacements ux and uy (points 3 and 54 at story 9); (b) base shear in X and $\mathrm{Y}$ directions; (c) shear forces in wall X1; (d) shear forces in wall X2; (e) time snapshots of failure mechanisms' development at story 5.

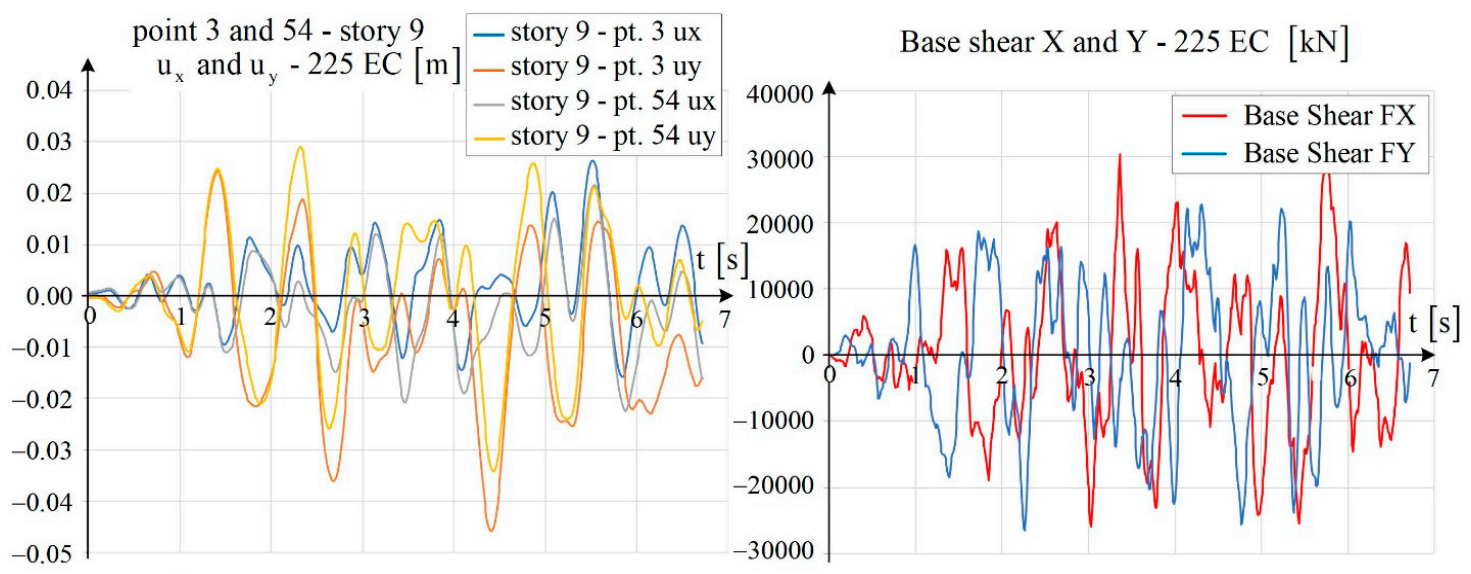

(a)

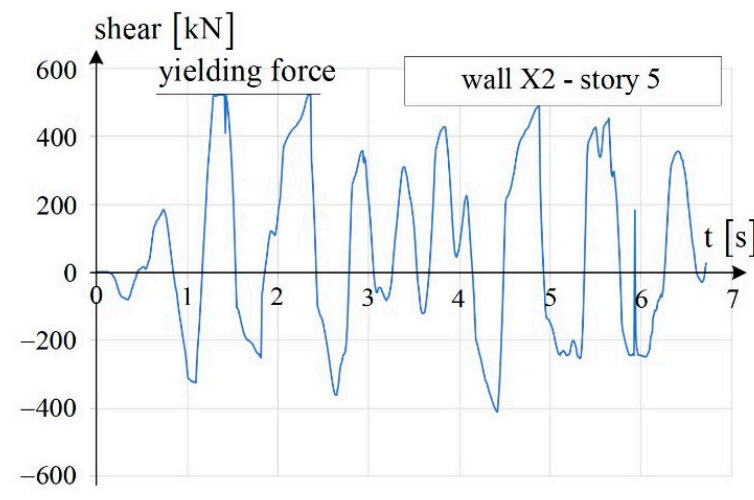

(c) (b)

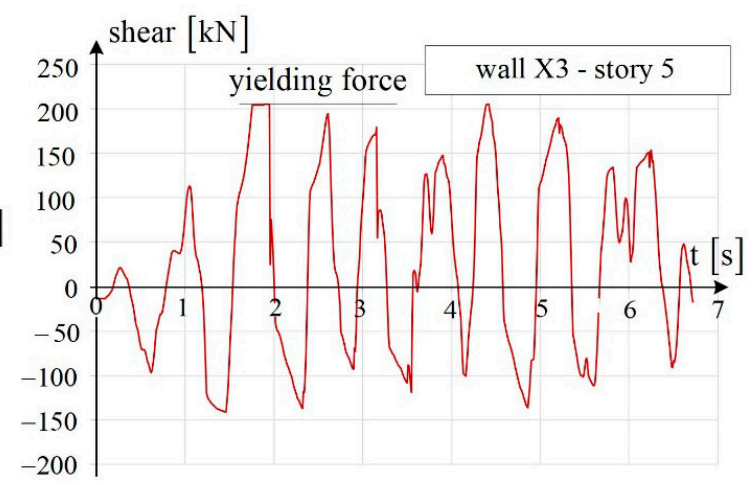

(d)

Figure 24. Earthquake scenario for 225 y RP-EC8: (a) top displacements ux and uy (points 3 and 54 at story 9); (b) base shear in the X and Y directions; (c) shear forces in wall X2; (d) shear forces in wall X3. 


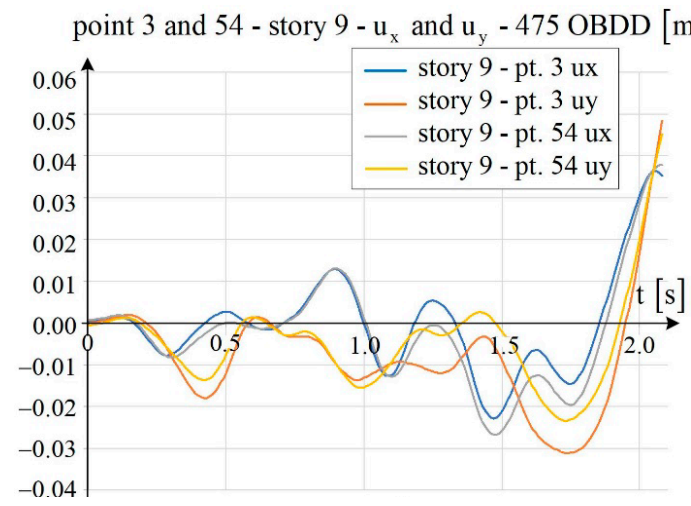

(a)

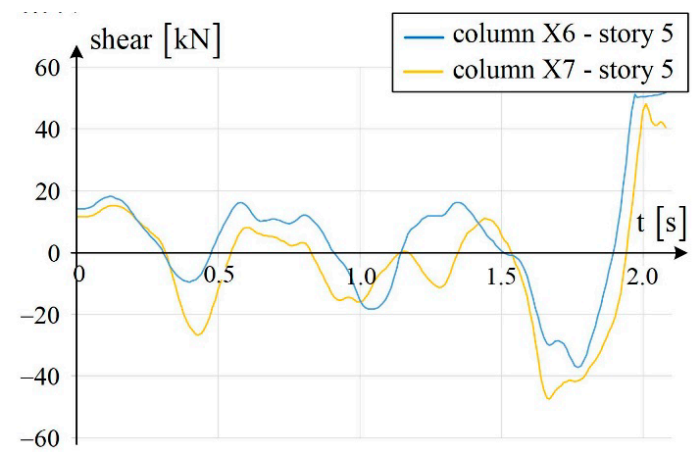

(c)

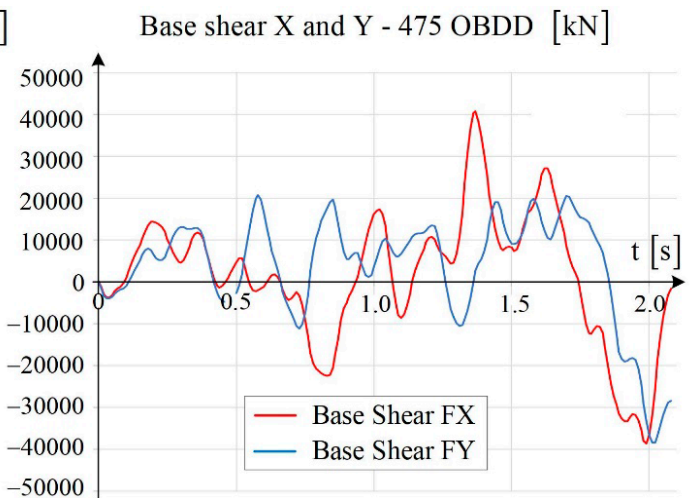

(b)

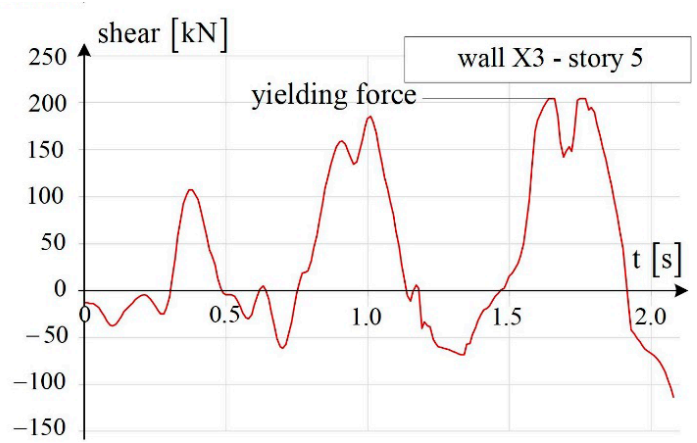

(d)

Figure 25. Earthquake scenario for 475 y RP-OBDD: (a) top displacements ux and uy (points 3 and 54 at story 9); (b) base shear in the X and Y directions; (c) shear forces in columns X6 and X7; (d) shear forces in wall X3.

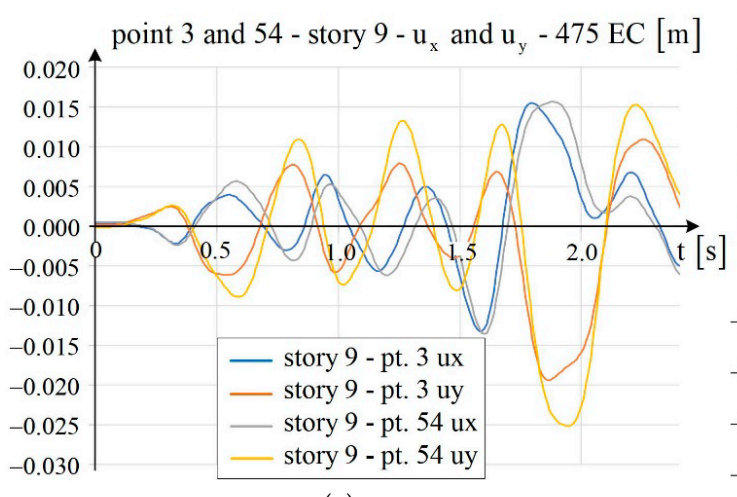

(a)

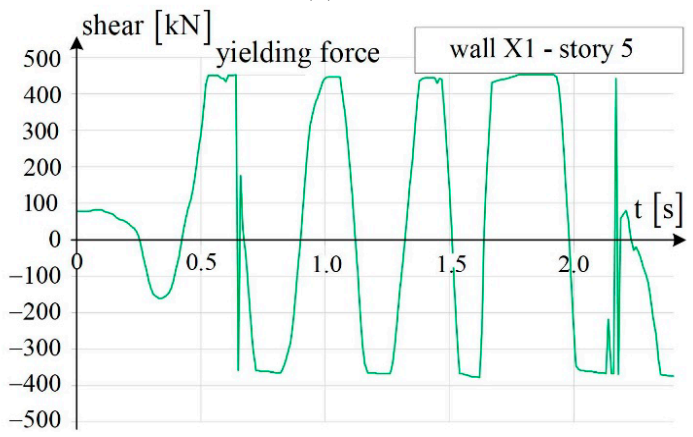

(c)

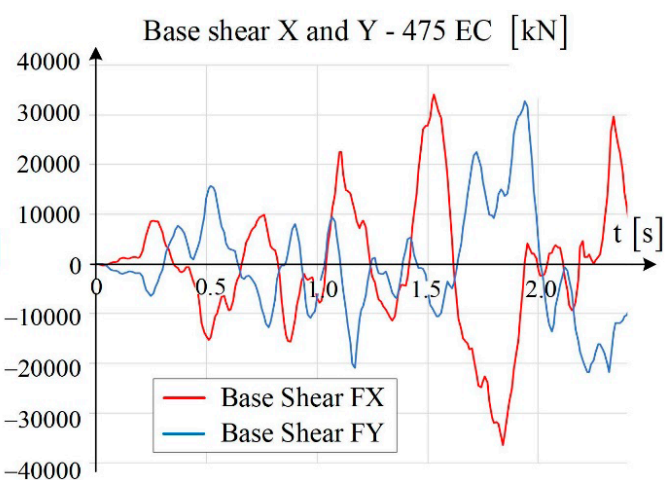

(b)

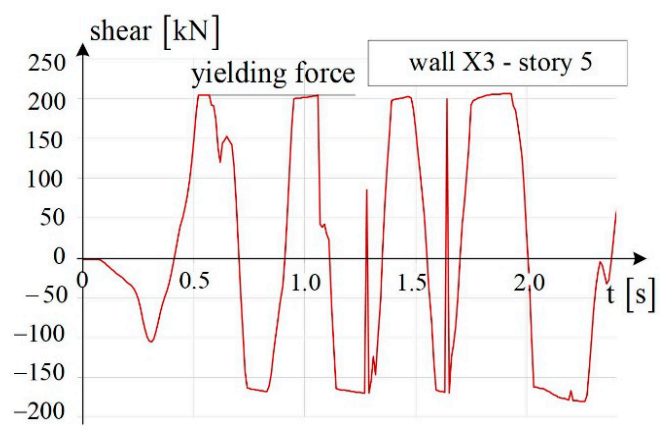

(d)

Figure 26. Cont. 

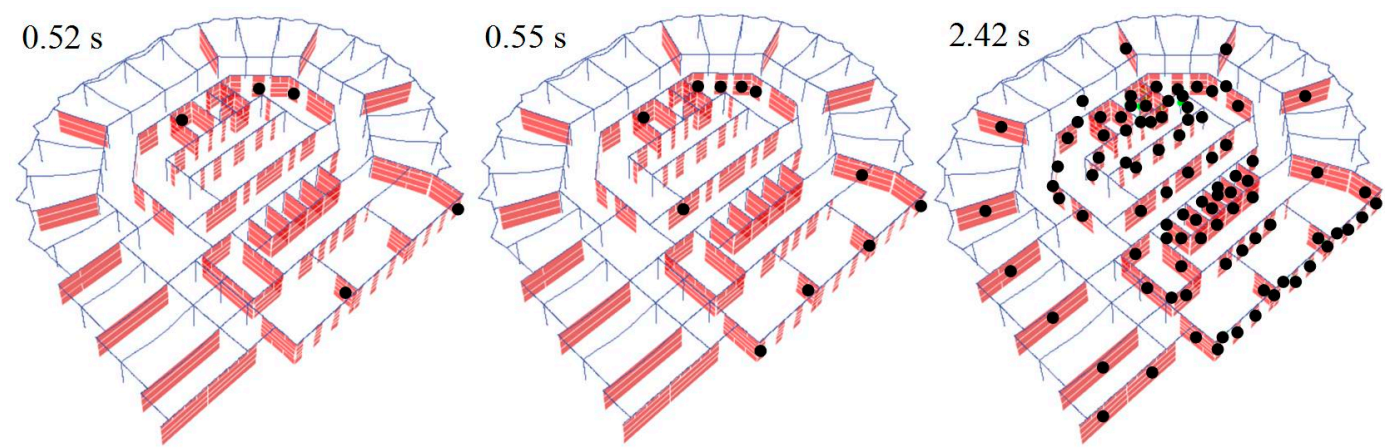

(e)

Figure 26. Earthquake scenario for 475 y RP-EC8: (a) top displacements ux and uy (points 3 and 54 at story 9); (b) base shear in the X and Y directions; (c) shear forces in wall X1; (d) shear forces in wall X3; (e) time snapshots of failure mechanisms' development at story 5.

\section{Discussion}

The reliability of the presented results depends primarily on the accuracy of input data, such as variations of the material quality, assumptions related to structural detailing, as-built reinforcements, existing structural damage, soil conditions, etc. Exhaustive non-destructive experimental measurements were performed and the numerical models of various levels of complexity (from the simplest to the most complex ones) were created in order to achieve the best possible accuracy without performing destructive testing which would disrupt the functioning of the hospital.

The main structural features of the building, quantitatively and qualitatively determining the structural performance during earthquakes, will be summarized in the following text, including general observations based on the performed analysis and presented results:

- The structural system is mostly formed of RC (MB30) walls (25 cm), which continuously extend from the foundations to the roof. The building is irregular in height, especially at the transition from the second to third story above ground level. Analyses confirmed that the critical structural elements are mostly located on the third floor above ground level where the total cross-section area of walls (in plan) is much smaller than on the ground floor. Moreover, the area of walls is much smaller in the $Y$ direction, so this represents the most detrimental earthquake direction. The frame system on the building perimeter contributes minimally with its stiffness to the overall structural load-bearing capacity to resist horizontal loads, but it is very important for transferring vertical loads.

- The main deficiency of primary elements (walls, columns, beams and coupled beams) is their shear capacity. Analyses showed that shear reinforcement was insufficient in most of the elements, and could initiate brittle failure, which happened suddenly. Another problem is the boundary zones in walls, which are not confined by transversal reinforcement which is necessary for achieving ductility (at least before the redistribution of the force to adjoining elements).

- The deficiency related to the lack of ductility is additionally emphasised by the use of smooth reinforcement bars (GA240) and questionable anchoring lengths and lap splices (with regard to modern seismic regulations). In some beams, longitudinal reinforcement ratios are very high, which significantly reduces their ductility.

- Plan irregularity increases the torsional effects on the structural elements of the building perimeter at the south-west part. The reason is the relatively stiff north-east and central building parts (location of the stiffness centre is in the vicinity of the main staircase). Sensitivity to torsional vibrations may be observed in structural vibration modes, determined numerically and experimentally. The first vibration mode represents an almost regular translation in the $Y$ direction, while the second mode comprises a significant torsional contribution to the translation 
in the $\mathrm{X}$ direction. Due to torsion, columns located near the building perimeter may be damaged even for low intensity earthquakes.

- Walls located at south and south-west part are significantly endangered due to insufficient transversal reinforcement and low ductility. Cracking and significant reduction of stiffness occurs very quickly followed by redistributions over by the adjoining walls. It should be pointed out that during cyclic loading the cracked wall does not return to its original position but remains damaged and maintains a reduced stiffness level. This process continues until a local mechanism is formed, which may lead to the local slab collapse which is confirmed by nonlinear analyses. The gradual cracking and decrease in stiffness of elements may be noticed on the pushover curve of the structure.

- The distribution of the RC partition walls (7 or $10 \mathrm{~cm}$ thick) is not regular in terms of height. These elements participate in structural responses for small amplitude excitations, but for high amplitude excitations it may be expected that their discrete connections will fail and walls may lose their stability. Although discrete anchorages to the floor system were defined by the original design, it was detected by visual inspection that these connections were not adequately built in.

- Due to the existing nuclear shelter, basement stories are much stiffer than those above ground level, so they are not significantly affected by seismic loads.

On the basis of the presented results of detailed numerical analysis, an engineering assessment of the expected performance of the building due to different earthquake scenarios is as follows:

- The 95 year return period earthquakes may cause local damage to the columns, but significant damage of the structural walls is not expected. Moreover, the damage in coupled beams, and the cracking and spalling of some non-structural elements, especially of partition walls, may be expected, which pose a potential danger for occupants. However, with regard to valid (modern) regulations [43], this earthquake intensity level corresponds to the limit state (LS) of damage limitation in which the structure should only be lightly damaged and would not need any repair measures, which could be significantly exceeded for this structure. According to the performed analyses, the LS of damage limitation is expected to be reached for a PGA of $0.08 \mathrm{~g}$ (not shown in the results). It should be pointed out that an earthquake of this return period roughly (according to the response of the structure) corresponds to the limit state to which the structure was designed in 1980, so it can be concluded that the structure meets the requirements according to which it was designed. As mentioned before, the results obtained using records simulated for a deterministic earthquake scenario are less unfavorable than the results obtained by artificial records matched to the prescribed response spectrum.

- The 225 year return period earthquakes may significantly affect the structural load-bearing capacity. The most vulnerable locations are the north façade wall with openings and the south-west area of the third story above ground level (marked as story five in figures). Local failures may also occur in the frame systems near edges of the structure. Generally, it can be said that structure is in the limit state of significant damage (SD).

- The 475 year return period earthquakes may induce failures of the main structural elements and the load-bearing capacity of the system may significantly be degraded. Failure mechanisms can be formed which can occur relatively fast and without significant plastic deformations. It should be emphasised that a global collapse of the structure at a large scale would probably not happen because a large number of plastic hinges should form and a great amount of energy dissipation (damping) will occur. This is the advantage of such a highly statically indeterminate system-and therefore, a globally very robust one-especially during cyclic loading. Regarding the modern seismic regulations, this earthquake intensity level corresponds to the limit state of significant damage (SD). For this state, it should be expected that structure has some residual lateral strength and vertical elements that are still capable of sustaining vertical loads after an earthquake, but the 
structure is likely to be uneconomic to repair. However, it is not to be expected that this structure can satisfy these demands.

The analysis for the 2475 year return period has shown that this level of earthquake intensity is too high for this building, so the results are not presented herein. The importance factor has not been explicitly mentioned in the performed analysis, but it is correlated with the earthquake return period and it can be applied to existing results.

The decision on required interventions for enhancing the seismic performance of a structure should be based on the performed assessment and extent of the damage. Furthermore, one of the most important criterions is the functionality of a structure that is needed during the earthquake and prevention of structural and non-structural damage. The decision on the type and scope of the retrofit should also account for social-economic aspects, such as retrofit costs, the importance of the building and the disruption of the use or occupancy during the intervention. When retrofitting structures of strategic importance, decisions should be in accordance with a cost-benefit analysis and an examination of different solutions.

According to the analyses, target retrofit measures can be proposed to prevent, at least, local mechanisms. As acceptance criteria for this building have not been established, retrofit strategies of minimal invasiveness will be recommended in order to enhance the structural safety and load-bearing capacity. It must be pointed out that the level of the structural load-bearing capacity demanded by modern seismic regulations for new hospital buildings would not be easily achieved, because it would be very expensive. However, these measures could reduce some structural deficiencies identified by calculations. In addition to the increase in the structural capacity of critical elements, the proposed interventions could improve the ductility of brittle elements.

Target strengthening of structural elements in critical building zones is recommended; this primarily refers to perimetric columns and beams which radially extend into the interior of the plan. It is recommended to extend existing elements or to construct new elements (columns) with the goal of preventing identified local failures. Frame structure elements can be also strengthened with steel or RC jackets, wrapping by fibre reinforced polymer (frp), etc. The ductility capacity of brittle walls may be increased with an application of high strength materials, such as frp, to walls and columns, where frp may be glued to the surface or wrapped around an element.

In addition to primary seismic elements (structural), secondary elements (non-structural) are also important. Partial or full collapses of these elements in these states should be avoided by increasing their capacity and appropriate anchoring to prevent fallouts.

An important conclusion based on the analysis is that horizontal and vertical corridors in the case of earthquake, especially stairs, are safe. In the observed building, the relatively safe spots include areas around central staircase and the elevator core. As the staircase is constructed monolithically, it was assumed that it will keep its load-bearing capacity and ductility until the collapse scenario.

\section{Conclusions}

This paper presents state-of-the-art methodology for a comprehensive seismic performance assessment using detailed multilevel numerical and experimental analyses, applied to an existing complex RC hospital building. The building load-bearing capacity, collapse mechanism and critical elements due to seismic action are determined for various earthquake scenarios. The results are shown and explained, which may further be used in applications to the most appropriate earthquake risk mitigation measures.

Due to large number of analyses performed and the output data, only the most important and representative results for gaining an insight into the expected seismic behavior of this irregular structure constructed as a wall system have been presented. It should be pointed out that the observations were mostly drawn from the nonlinear dynamic time-histories, the most accurate of all performed analyses. Artificial accelerograms, generated in accordance with the prescribed response spectrum, are very detrimental as they excite all the significant frequencies of the building, which has a very 
low probability of happening in an earthquake. The results highlight the unfavorable structural system regarding the stiffness distribution. The building irregularity in height affects critical structural elements mostly located on the third floor above ground level and the ground floor. Irregularities in the plan cause unfavorable torsional effects, especially in the critical walls located at the south and south-west of the core edge, and on the north façade. The main deficiency is the insufficient shear capacity of primary elements and a lack of ductility. The critical structural elements have clearly been identified and they may be continuously observed in the future (e.g., after low intensity earthquakes). The identification of these structural deficiencies may further be useful for planning prevention measures (evacuation routes) and for the targeted strengthening of the structure, or in less fortunate events, for the civil protection and intervention teams during rescue missions and in performing post-earthquake damage assessments.

Author Contributions: M.U., J.A. and M.S.N. performed the numerical analyses, while S.P. was in charge of the whole study presented herein, especially for the seismological part. M.U. and M.S.N. wrote the initial draft of the paper. J.A and S.P. checked the presented results and revised the paper. All authors have read and agreed to the published version of the manuscript.

Funding: This research was funded by European Regional Development Fund, in the scope of the Interreg Italy-Croatia project READINESS, Dubrovnik-Neretva County (application ID 10041704).

Acknowledgments: The authors would like to thank all colleagues from the Department of Geophysics, Faculty of Science, University of Zagreb and from the Department of Engineering Mechanics, Faculty of Civil Engineering, University of Zagreb, who took part in the study, partially presented in this paper. Authors would also like to thank Dubrovnik-Neretva County for supporting studies dealing with the mitigation of seismic risk, such as this one.

Conflicts of Interest: The authors declare no conflict of interest.

\section{References}

1. Wallemacq, P.; House, R. Economic Losses, Poverty and Disasters 1998-2017. In Centre for Research on the Epidemiology of Disasters; United Nations Office for Disaster Risk Reduction (UNDRR): Geneva, Switzerland, 2018.

2. Miniati, R.; Iasio, C. Methodology for rapid seismic risk assessment of health structures: Case study of the hospital system in Florence, Italy. Int. J. Disaster Risk Reduct. 2012, 2, 16-24. [CrossRef]

3. World Health Organization Europe Region Office (EURO). Health Facility Seismic Vulnerability Evaluation: A Handbook; Disaster Preparedness and Response Programme (DPR) Division of Country Support, Country Policies, Systems and Services (DCS/CPS) World Health Organization, Regional Office for Europe (WHO/EURO): Copenhagen, Denmark, 2006.

4. Nuti, V.; Santini, S.; Vanzi, I. Seismic Assessment of the Molise Hospitals and Upgrading Strategies. In Proceedings of the 13th World Conference on Earthquake Engineering, Vancouver, BC, Canada, 1-6 August 2004.

5. D'Ayala, D.; Galasso, C.; Minas, S.; Novelli, V. Review of Methods to Assess the Seismic Vulnerability of Buildings, with Particular Reference to Hospitals and Medical Facilities; Evidence on Demand: London, UK, 2015.

6. Masi, A.; Santarsiero, G.; Chiauzzi, L. Vulnerability Assessment and Seismic Risk Reduction Strategies of Hospitals in Basilicata Region (Italy). In Proceedings of the 15th World Conference on Earthquake Engineering-WCEE, Lisbon, Portugal, 24-28 September 2012; pp. 1-10.

7. Yu, P.; Wen, W.; Ji, D.; Zhai, C.; Xie, L. A framework to assess the seismic resilience of urban hospitals. Adv. Civ. Eng. 2019, 2019. [CrossRef]

8. Perrone, D.; Aiello, M.A.; Pecce, M.; Rossi, F. Rapid visual screening for seismic evaluation of RC hospital buildings. Structures 2015, 3, 57-70. [CrossRef]

9. Karapetrou, S.; Manakou, M.; Bindi, D.; Petrovic, B.; Pitilakis, K. “Time-building specific” seismic vulnerability assessment of a hospital RC building using field monitoring data. Eng. Struct. 2016, 112, 114-132. [CrossRef]

10. Estêvão, J.M.C. An integrated computational approach for seismic risk assessment of individual buildings. Appl. Sci. 2019, 9. [CrossRef]

11. Ferraioli, M. Case study of seismic performance assessment of irregular RC buildings: Hospital structure of Avezzano (L'Aquila, Italy). Earthq. Eng. Eng. Vib. 2015, 14, 141-156. [CrossRef] 
12. La Brusco, A.; Mariani, V.; Tanganelli, M.; Viti, S.; De Stefano, M. Seismic assessment of a real RC asymmetric hospital building according to NTC 2008 analysis methods. Bull. Earthq. Eng. 2015, 13, 2973-2994. [CrossRef]

13. Massone, L.M.; Bonelli, P.; Lagos, R.; Lüders, C.; Moehle, J.; Wallace, J.W. Seismic design and construction practices for RC structural wall buildings. Earthq. Spectra 2012, 28. [CrossRef]

14. Fischinger, M.; Isaković, T.; Kolozvari, K.; Wallace, J. Guest editorial: Nonlinear modelling of reinforced concrete structural walls. Bull. Earthq. Eng. 2019, 17, 6359-6368. [CrossRef]

15. Caruso, C.; Bento, R.; Castro, J.M. A contribution to the seismic performance and loss assessment of old RC wall-frame buildings. Eng. Struct. 2019, 197, 109369. [CrossRef]

16. Deger, Z.T.; Wallace, J.W. Collapse Assessment of the Alto Rio Building in the 2010 Chile Earthquake. Earthq. Spectra 2015, 31, 1397-1425. [CrossRef]

17. Araya-letelier, G.; Parra, P.F.; Lopez-garcia, D.; Garcia-valdes, A.; Candia, G.; Lagos, R. Collapse risk assessment of a Chilean dual wall-frame reinforced concrete office building. Eng. Struct. 2019, 183, 770-779. [CrossRef]

18. Ugalde, D.; Parra, P.F.; Lopez-Garcia, D. Assessment of the seismic capacity of tall wall buildings using nonlinear finite element modeling. Bull. Earthq. Eng. 2019, 17, 6565-6589. [CrossRef]

19. Karimiyan, S.; Moghadam, A.S.; Karimiyan, M.; Kashan, A.H. Seismic collapse propagation in 6-story RC regular and irregular buildings. Earthq. Struct. 2013, 5, 753-779. [CrossRef]

20. Roohi, M.; Hernandez, E.M. Performance-based post-earthquake decision making for instrumented buildings. J. Civ. Struct. Heal. Monit. 2020. [CrossRef]

21. Sinkovič, K.; Peruš, I.; Fajfar, P. Assessment of the seismic performance of low-rise RC structures by procedures with different levels of complexity. Bull. Earthq. Eng. 2016, 14, 213-239. [CrossRef]

22. Prevolnik, S.; Herak, M.; Dasović, I.; Fiket, T.; Ivančić, I.; Kuk, K.; Markušić, S.; Mustać, M.; Sović, I.; Stipčević, J.; et al. Seismic Performance Assessment of BUILDING D of General Hospital Dubrovnik; University of Zagreb, Faculty of Science, Department of Geophysics and University of Zagreb, Faculty of Civil Engineering, Department of Engineering Mechanics, Interreg Readiness, Italy-Croatia; European Regional Development Fund, EU: Zagreb, Croatia, 2019.

23. Brincker, R.; Zhang, L.; Andersen, P. Modal identification of output-only systems using frequency domain decomposition. Smart Mater. Struct. 2001, 10, 441-445. [CrossRef]

24. Reynders, E. System Identification Methods for (Operational) Modal Analysis: Review and Comparison. Arch. Comput. Methods Eng. 2012, 19, 51-124. [CrossRef]

25. Zhang, L.; Wang, T.; Tamura, Y. A frequency-spatial domain decomposition (FSDD) method for operational modal analysis. Mech. Syst. Signal Process. 2010, 24, 1227-1239. [CrossRef]

26. Atalić, J.; Šavor Novak, M.; Uroš, M. Updated risk Assessment of Natural Disasters in Republic of Croatia-Seismic Risk Assessment; Faculty of Civil Engineering in collaboration with Ministry of Construction and Physical Planning and National Protection and Rescue Directorate: Zagreb, Croatia, 2018. (In Croatian)

27. Atalić, J.; Novak, M.Š.; Uroš, M. Seismic risk for Croatia: Overview of research activities and present assessments with guidelines for the future. Građevinar 2019, 71, 923-947. [CrossRef]

28. Šavor Novak, M.; Atalić, J.; Uroš, M.; Herak, M.; Demšić, M.; Baniček, M.; Lazarević, D.; Bijelić, N.; Crnogorac, M.; Todorić, M. 22 March 2020 Zagreb, Croatia Earthquake: Preliminary Report on Seismological Aspects and Observed Damage. GRADEVINAR under review.

29. HZN. HRN EN 1998-1, Eurocode 8: Design of Structures for Earthquake Resistance-Part 1: General Rules, Seismic Actions and Rules for Buildings; HZN: Zagreb, Croatia, 2011. (In Croatian)

30. SFRY Official Gazette. Code of Technical Regulations for the Construction of Building in Seismic Areas, SFRJ 31/81, 49/82, 29/83, 20/88, 52/90; SFRY Official Gazette: Belgrade, Socialist Federal Republic of Yugoslavia, 1981. (In Croatian)

31. Nakamura, Y. A method for dynamic characteristics estimation of subsurface using microtremor on the ground surface. Quart. Rep. Railw. Tech. Res. Inst. 1989, 30, 25-33.

32. Google Maps, 2019. 1:4.200. Available online: https://www.google.com/maps (accessed on 20 February 2019).

33. Herak, M.; Allegretti, I.; Herak, D.; Ivančić, I.; Kuk, V.; Marić, K.; Markušić, S.; Sović, I. Republic of Croatia, Seismic Hazard Map, 2011. Available online: http://seizkarta.gfz.hr (accessed on 20 February 2019).

34. Lee, V.; Herak, M.; Herak, D.; Trifunac, M.D. Uniform hazard spectra in North-western Bosna and Hercegovina. Izgradnja 2010, 64, 282-304. 
35. Lee, V.; Trifunac, M.D.; Herak, M.; Herak, D. Uniform hazard earthquake acceleration spectra in Kraljevo-Contributions from local seismicity. Izgradnja 2011, 65, 227-235.

36. Lee, V.; Trifunac, M.D.; Herak, M.; Herak, D. Minimum radius of seismic activity for earthquake hazard analyses. Izgradnja 2011, 65, 219-226.

37. Lee, V.; Herak, M.; Herak, D.; Trifunac, M. Uniform hazard spectra in western Balkan Peninsula. Soil Dyn. Earthq. Eng. 2013, 55, 1-20. [CrossRef]

38. Gasparini, D.; Vanmarcke, E.H. Simulated Earthquake Motions Compatible with Prescribed Response Spectra; M.I.T. Department of Civil Engineering, Constructed Facilities Division, National Technical Information Service, U.S. Department of Commerce: Springfield, VA, USA, 1976.

39. Seismosoft. SeismoArtif 2018-A Computer Program for Generating Artificial Earthquake Accelerograms Matched to a Specific Target Response Spectrum; Seismosoft Ltd.: Pavia, Italy, 2018.

40. Trifunac, M.D. Broad Band Extension of Fourier Amplitude Spectra of Strong Motion Acceleration; Report No. 93-01; Department of Civil Engineering, University of Southern California: Los Angeles, CA, USA, 1993.

41. Lee, V.; Trifunac, M.D. Frequency Dependent Attenuation Function and Fourier Amplitude Spectra of Strong Earthquake Ground Motion in California; Report No. 95-03; Department of Civil Engineering, University of Southern California: Los Angeles, CA, USA, 1995.

42. Trifunac, M.D.; Brady, A.G. A study on the duration of strong earthquake ground motion. Bull. Seismol. Soc. Am. 1975, 65, 581-626.

43. CSI. CSI Analysis Reference Manual For SAP2000, ETABS, SAFE and CSiBridge; Computers and Structures, Inc.: Berkeley, CA, USA, 2011.

44. HZN. HRN EN 1998-3, Eurocode 8: Design of Structures for Earthquake Resistance-Part 3: Assessment and Retrofitting of Buildings; HZN: Zagreb, Croatia, 2011. (In Croatian)

45. ASCE. Seismic Rehabilitation of Existing Buildings, ASCE/SEI 41-13; American Society of Civil Engineers: Reston, VA, USA, 2014; ISBN 9780784412855.

46. NIST. Recommended Modeling Parameters and Acceptance Criteria for Nonlinear Analysis in Support of Seismic Evaluation, Retrofit, and Design, NIST GCR 17-917-45; Applied Technology Council for the National Institute of Standards and Technology: Gaithersburg, MD, USA, 2017.

47. NIST. NEHRP Seismic Design Technical Brief No. 4: Nonlinear Structural Analysis for Seismic Design: A Guide for Practicing Engineers, NIST GCR 10-917-5; NEHRP Consultants Joint Venture, a partnership of the Applied Technology Council and the Consortium for Universities for Research in Earthquake Engineering, for the National Institute of Standards and Technology: Gaithersburg, MD, USA, 2010.

48. NIST. Guidelines for Nonlinear Structural Analysis and Design of Buildings, Part I—General, NIST GCR 17-917-46v1; Applied Technology Council for the National Institute of Standards and Technology: Gaithersburg, MD, USA, 2017.

49. FEMA. NEHRP Guidelines for the Seismic Rehabilitation of Buildings, FEMA 273; Applied Technology Council for Federal Emergency Management Agency: Washington, DC, USA, 1997.

50. FEMA. NEHRP Commentary on the Guidelines for the Seismic Rehabilitation of Buildings, FEMA 274; Applied Technology Council for Federal Emergency Management Agency: Washington, DC, USA, 1997.

51. FEMA. Prestandard and Commentary for the Seismic Rehabilitation of Buildings, FEMA 356; American Society of Civil Engineers for the Federal Emergency Management Agency: Washington, DC, USA, 2000.

52. FEMA. Seismic Performance Assessment of Buildings, FEMA P-58; Applied Technology Council for Federal Emergency Management Agency: Washington, DC, USA, 2012.

53. FIB. Seismic Assessment and Retrofit of Reinforced Concrete Buildings, STATE-of-the-Art Report Prepared by Task Group 7.1; FIB: Lausanne, Switzerland, 2003; bulletin 24.

54. Grammatikou, S.; Biskinis, D.; Fardis, M.N. Strength, deformation capacity and failure modes of RC walls under cyclic loading. Bull. Earthq. Eng. 2015, 3277-3300. [CrossRef]

55. Grammatikou, S.; Fardis, M.N. Models of the flexure-controlled strength, stiffness and cyclic deformation capacity of rectangular RC columns with smooth bars, including lap-splicing and FRP jackets. Bull. Earthq. Eng. 2018, 16, 341-375. [CrossRef]

56. Sánchez-Alejandre, A.; Alcocer, S.M. Shear strength of squat reinforced concrete walls subjected to earthquake loading-trends and models. Eng. Struct. 2010, 32, 2466-2476. [CrossRef]

57. Terzioglu, T.; Orakcal, K.; Massone, L.M. Cyclic lateral load behavior of squat reinforced concrete walls. Eng. Struct. 2018, 160, 147-160. [CrossRef] 
58. HZN. HRN EN 1992-1-1, Eurocode 2: Design of Concrete-Part 1-1: General Rules and Rules for Buildings; HZN: Zagreb, Croatia, 2013. (In Croatian)

59. ACI. Building Code Requirements for Structural Concrete and Commentary, ACI 318-14; American Concrete Institute: Farmington Hills, MI, USA, 2014.

60. Parra, P.F.; Arteta, C.A.; Moehle, J.P. Modeling criteria of older non-ductile concrete frame-wall buildings. Bull. Earthq. Eng. 2019, 17, 6591-6620. [CrossRef]

61. Christidis, K.I.; Trezos, K.G. Experimental investigation of existing non-conforming RC shear walls. Eng. Struct. 2017, 140, 26-38. [CrossRef]

62. Belletti, B.; Damoni, C.; Gasperi, A. Modeling approaches suitable for pushover analyses of RC structural wall buildings. Eng. Struct. 2013, 57, 327-338. [CrossRef]

(C) 2020 by the authors. Licensee MDPI, Basel, Switzerland. This article is an open access article distributed under the terms and conditions of the Creative Commons Attribution (CC BY) license (http://creativecommons.org/licenses/by/4.0/). 